Attention, Mindwandering, and Mood

Attention, Mindwandering, and Mood

Michael H. Hobbiss ${ }^{*}$, Jake Fairnie, Keya Jafari and Nilli Lavie

Institute of Cognitive Neuroscience, University College London

*Corresponding author

Email: michael.hobbiss.15@ucl.ac.uk; michael.hobbiss@gmail.com

Word count (text and references): 10710

Keywords:

Attention focus; irrelevant distraction; mindwandering; happiness; mood 


\title{
Attention, Mindwandering, and Mood
}

\begin{abstract}
We tested the hypothesis that mindwandering and external distraction are both manifestations of a common state of reduced attention focus, and examined how both relate to reported level of happiness. We conducted real-time sampling of people's experience of mindwandering and distraction, irrelevant distractions (e.g. music, phone, etc.), and happiness levels, in two studies with 524 people undertaking common daily-life activities. All irrelevant external distractions were positively correlated with mindwandering. Indeed mindwandering duration could be predicted from the duration of external distraction, when controlling for a range of background variables. An exploratory factor analysis of mindwandering and distraction reports suggested a single underlying construct. In addition, duration of irrelevant distraction by both mobile phones and mindwandering was significantly associated with reduced reported levels of happiness. The results are consistent with the hypothesis that that a state of reduced attention focus underlies both mindwandering and distractibility and clarify the link with happiness.
\end{abstract}




\section{Attention, Mindwandering, and Mood}

\section{Introduction}

Despite our best efforts, we may often find ourselves distracted by entirely irrelevant stimuli. A person passing by, birdsong, or a new message notification sound on our phone or computer can all distract us from reading this article. In addition, even in the absence of any external distraction we may find our mind wandering into unrelated topics, again distracting us from our current goal of reading. Although the topics of mindwandering and attention focus (or conversely distractibility), have been typically studied separately, a growing body of studies has begun to directly investigate the relationship between them. Indeed, some researchers argue that both reflect a common failure of attention focus, as long as the external distractors are entirely irrelevant to the task at hand (e.g. Forster \& Lavie 2014).

In the present research, we examine the relationship between irrelevant distraction and mindwandering further, predicting that they should be positively correlated in people's reports about daily life experience, as would be expected if they both reflect a state of reduced attention focus. In addition, as a large study of mindwandering in daily life reported that mindwandering was linked to lower levels of happiness (Killingsworth \& Gilbert, 2010) here we examine also whether this relationship replicates in a different setup, and whether it may also apply to external distraction. We predicted that if the relationship of mindwandering and happiness is driven by a state of reduced ability to maintain attention focus then irrelevant distractions should also be associated with reduced levels of happiness. Next we briefly review the relevant research on distractibility, mindwandering and the potential relationship between reduced attention focus and mood. 


\section{Attention, Mindwandering, and Mood}

\subsection{The relationship between mindwandering and external distraction}

Much research has demonstrated the interfering effects of both external distractions and mindwandering on task performance. For example, the addition of distractor stimuli during visual search tasks leads to slower response times compared with distractor-absent trials (Forster \& Lavie, 2007; Lavie, 1995; Lavie \& Cox, 1997; Lavie, Hirst, De Fockert \& Viding, 2004; see Lavie, 2005; 2010 for reviews) even when the distractors are entirely irrelevant to the task at hand (e.g. Forster \& Lavie, 2008a; b). In a similar vein, mindwandering research has demonstrated that a higher frequency of task-unrelated thought (TUT) reports is associated with increased errors in go/no-go tasks and in antisaccade tasks (McVay \& Kane, 2009; Smallwood et al., 2004; Kane et al., 2017). Higher number of reports of both mindwandering and irrelevant distractions was also found to be associated with slower reaction times and increased variability in reaction times (e.g. Stawarczyk, Majerus, Maj, Van der Linden \& D'Argembeau, 2011; Stawarczyk, Majerus, Catale \& D’Argembeau, 2014) on the Sustained Attention to Response Task (SART), though in some cases mindwandering was associated with a greater effect on the RT than the distraction reports (see Stawarczyk et al., 2014).

Distractor interference effects have been directly related to mindwandering in a series of studies that assessed both distractor interference effects and the occurrence of task unrelated thoughts. Forster and Lavie (2009) incorporated TUT probes into the irrelevant distractor paradigm (originated by Forster and Lavie, 2008a; b). A letter search task in which a brightly coloured task-irrelevant distractor stimulus (an image of famous cartoon characters) appeared at a peripheral location during a minority of trials. During blocks of either low or high perceptual load in the search task (varied by the target and non-target letter similarity), participants were intermittently probed as to whether their current thought was 


\section{Attention, Mindwandering, and Mood}

task-related or task-unrelated. Increased perceptual load did not only reduce irrelevant distractor interference effects but also reduced mindwandering reports thus demonstrating that both external distraction and "internal distraction" in the form of TUTs are modulated by a common attentional mechanism.

Forster and Lavie (2014) established a direct relationship between mindwandering and external distraction and suggested these can both be classed as manifestations of reduced attention focus, leading to greater distractibility towards both external sources (task-irrelevant stimuli) or internal sources (task-irrelevant thoughts, i.e. mindwandering). They tested this hypothesis in an individual differences study and found that the rate of everyday mindwandering reports (on the Daydreaming Frequency sub scale of the Imaginal Processes Inventory; DDFS; Singer \& Antrobus, 1970) was positively correlated with the magnitude of distractor interference from task-irrelevant stimuli (cartoon images presented in the periphery during a letter search task). The positive correlation with the rate of mindwandering was only found for these entirely irrelevant distractors. Response competition effects from the same cartoon images when these were made task relevant (either congruent or incongruent with response to target names, producing response competition effects) were not associated with mindwandering. Forster and Lavie concluded that task-irrelevance is an important consideration in the relationship between mindwandering and external distraction, in support of their proposal that a common attentional mechanism (i.e. reduced ability to focus on task relevant material) underlies distraction from task-irrelevant sources, both external and internal.

The relationship of mindwandering and irrelevant distraction was further examined in a series of studies by Stawarczyk and colleagues (Stawarczyk et al., 2011; Stawarczyk, 


\section{Attention, Mindwandering, and Mood}

Majerus, Maquet \& D’Argembeau 2011; Stawarczyk, Majerus, Van der Linden \& D’Argembeau, 2012; Stawarczyk et al., 2014; Stawarczyk \& D'Argembeau, 2016). These studies investigated the relationship between the frequency of TUT reports and reports about thoughts concerning task-irrelevant distractions, with both assessed by probe questions during performance of the SART. The probes allowed for a clear distinction between taskrelevant and irrelevant experiences, allowing 'stimulus-independent task-unrelated thoughts' (mindwandering) and 'stimulus-dependent task-unrelated thoughts' (external distractions) to be differentiated from task-related thoughts (as well as from each other). Using this design, Stawarczyk et al. (2014) and Stawarczyk \& D'Argembeau (2016) reported that the frequencies of mindwandering and external distraction reports were not significantly correlated. In addition, while mindwandering TUT reports were found to correlate significantly to the DDFS, irrelevant distraction reports were not (see Stawarczyk et al., 2012; 2014; Stawarczyk \& D'Argembeau, 2016). Although these results may appear incompatible with the conclusions of Forster and Lavie (2014) we note that the response options for participants did not allow participants to report both mindwandering and external distraction in response to the same probe (e.g. Stawarczyk, et al., 2011a; Stawarczyk, et al., 2011b; Stawarczyk et al., 2014), whereas both reports might be expected during a period of reduced attention focus on the task. This restriction is likely to limit the strength of any relationship between the two variables, and is therefore not ideally suited to demonstrating how mindwandering and external distraction relate to one another over time. Moreover, the nature of irrelevant external distractions measured in the rather quiet and distractionimpoverished settings of lab testing could potentially restrict any relationship to mindwandering in daily life as measured by the DDFS. In a task using highly salient visual distractors, depicting images of famous characters, Forster and Lavie (2014) did find that external distractions in the laboratory correlated to mindwandering rates on the DDFS. 


\section{Attention, Mindwandering, and Mood}

Unsworth and McMillan (2014) also assessed the relationship of mindwandering reports and external distraction reports using thought probes. They used probe questions (repeated across five attention control tasks) that involved a distinct probe for reports of mindwandering ("I am zoning out/my mind is wandering") versus reports of external distraction ("I am distracted by information present in the room (sights and sounds)"). As in the studies of Stawarczyk et al., participants were only able to select one response from the probe options, so both options of mindwandering and external distraction could not be reported about their current experience in response to the same probe. When probe responses were modelled using a latent variable analysis, a model where external distractions and mindwandering loaded onto distinct latent variables was superior to one where they both loaded on a single variable. These factors were however strongly correlated with one another, and moreover, in a model that assessed common variance between all probe reports and performance on the attention control tasks, a single 'general attention' latent factor was formed, albeit with residual mindwandering and external distraction factors. Whilst these results clearly illustrate that mindwandering and external distraction appear to share a good deal of variance in common, the findings that a model in which external distractions and mindwandering loaded onto distinct latent variables was superior to one where they both loaded on a single variable (as well as the findings of residual, separate mindwandering and external distraction factors apart from the 'general attention' factor) might at first sight appear inconsistent with Forster and Lavie's suggestion that both are driven by the same 'reduced attention focus' mechanism. A few aspects of the study preclude a clear conclusion on this matter however. Firstly, the fact that each of the mindwandering and external distraction measures consisted of repetition of the very same probe response across five tasks, should have led to a greater correlation within a measure than between two different 


\section{Attention, Mindwandering, and Mood}

measures (with different probe questions), resulting in separate latent variables. Secondly regarding the residual variables, apart from the 'general attention' factor it is important to note that the attention control tasks used by Unsworth et al. did not explicitly measure taskirrelevant distraction (which Forster and Lavie showed to relate to mindwandering), but instead measured task-relevant response competition effects. Thirdly, as we mention earlier, the response measures precluded the reporting of mindwandering and external distraction on the same probe. Taken together these factors raise the possibility that the study measures lacked the sensitivity to demonstrate the sort of relationship between mindwandering and external distraction that might be expected on a shared mechanism of reduced attention focus account.

Unsworth, McMillan, Brewer \& Spillers (2012) asked college students to keep a diary of their cognitive failures over the course of one week, which did allow for the reporting of both mindwandering and external distraction within the same diary entry. Participants' records included those in which their attention was distracted from a task by an irrelevant stimulus in the external environment ("e.g. a flat-mate's phone ringing"), as well as incidents of mindwandering (“e.g. during a class lesson”), among other types of cognitive failures (e.g. memory failures). Unsworth et al. found a significant positive correlation between the total number of diarised mindwandering and irrelevant distractions, demonstrating their potential association in college student life (see also Unsworth, Brewer, and Spillers, 2012 and Unsworth \& McMillan, 2017, for similar findings). Unsworth and colleagues results have broken new ground, especially by relating the everyday experience of both mindwandering and external distractions (as well as other cognitive failures) to academic success. However, a diary study relies on participants intentionally choosing when to record attention states. As the act of engaging in the diary recording is in itself irrelevant to any of their daily tasks, it 


\section{Attention, Mindwandering, and Mood}

may be inherently biased to being used during states of overall reduced attention focus which involves intentional mindwandering as well as other external diversions towards irrelevant distractions. For example, a student present in a lecture that they may find boring may enter a state of reduced attention focus in which they may engage in mindwandering, listen intently to other people talking, check their mobile phone notifications etc., and in which they may also be more likely to record their experiences in the diary as a form of task-avoidance. While consistent with our hypothesis that a state of reduced attention focus should involve both mindwandering and irrelevant distraction, it remains plausible that there are cases of irrelevant distraction without mindwandering and vice versa and these were not recorded, simply because these cases lacked the intention to disengage attention from current task or activity to make a diary recording. In other words, a diary method may not be best suited to reveal whether unintentional disengagement of attention focus (e.g. in the form of unintentional mindwandering) is also associated with increased external distraction and vice versa.

In addition, it is not known whether the association of mindwandering and external distraction findings will persist across a wider variety of everyday activities, and across the richer forms of distraction prevalent in daily life (rather than simply the college environment), and across a more diverse sample of the whole population. Finally, since the diary reports did not include the source of external distraction (e.g. mobile phone, noise, people etc.), it remains unclear whether mindwandering is only associated with some types of external distraction but not others.

\subsection{Mindwandering, External Distraction and Mood}




\section{Attention, Mindwandering, and Mood}

Previous research has reported a relationship between depression or dysphoria and the frequency of mindwandering; and in a separate body of studies, a link between depression and the level of distractor interference effects. For example, Smallwood, O'Connor, Sudbery \& Obonsawin (2007) found that dysphoric students (i.e. those scoring highly on a depression inventory without meeting the criteria for clinical depression) reported more frequent mindwandering whilst performing a cognitive test and their mindwandering negatively affected performance on a main task more than in the non-depressed group. Participants scoring highly on the Beck Depression Inventory also report more frequent mindwandering whilst completing a SART, as well as reduced dispositional mindfulness (Deng, Li \& Tang, 2014). Self-reported mindwandering frequency in everyday life has also been linked to negative affect and increased self-report of depressive symptoms (Stawarczyk, Majerus, Van der Linden \& D’Argembeau., 2012; Mrazek, Phillips, Franklin, Broadway \& Schooler, 2013).

Elevated levels of distraction from external stimuli have also been noted for people reporting low levels of mood. Students with higher scores on the Beck Depression Inventory have been found more distractible on the 'emotional Stroop' test compared to those with lower scores, exhibiting greater delayed identification of the colour of words with negative (vs. neutral) emotional connotations (Gotlib \& McCann, 1984). While this effect might be partially explained by higher sensitivity to negative stimuli in depression, clinically depressed people also display performance deficits on attentional tests with emotionally-neutral stimuli, suggesting there may be a relationship between attention focus and mood. In a version of the Continuous Performance Test, for example, Cornblatt, Lenzenweger and ErlenmeyerKimling (1989) found that depressed individuals were more adversely affected by an auditory or visual distractor when detecting two identical stimuli (such as numbers or shapes) 


\section{Attention, Mindwandering, and Mood}

presented in a sequence. Similarly, Gohier et al. (2009) found a larger distractor-related impairment of reading comprehension in depressed patients compared to non-depressed controls. Importantly these effects were found not just for emotional but also emotionallyneutral or semantically-related distractor words.

The finding of elevated levels of distraction and mindwandering in cases of existing low-mood, even by emotionally-neutral material, does not inform about the relationship between attention focus and level of mood in the mentally-healthy population. Evidence exists, however, to suggest that in the case of mindwandering the connection persists in everyday life and among participants reporting normal ranges of moods. Killingsworth and Gilbert (2010) examined both the rate of mindwandering and ratings of mood during everyday activities in a large sample of 2250 participants. Participants responded to a phone application reporting their activities, ongoing emotions and mindwandering episodes (upon randomly timed probes). The results demonstrated that lower levels of mood were reported during periods of mindwandering compared to when people reported being "on task". As might be expected, this effect was larger for mindwandering with negative content but even neutral unrelated thoughts were associated with negative mood (and largely replicated by Franklin et al., 2013, though see Poerio, Totterdell \& Miles, 2013 for replicating the correlation of mindwandering and negative mood only for unrelated thoughts of negative content). In another study in which students responded to experience sampling questionnaires at regular intervals over the course of one week, Kane et al. (2017) found that reports of mindwandering were more likely to coincide with reports of experiencing more negative affect (feeling anxious, sad, irritable or confused). 


\section{Attention, Mindwandering, and Mood}

Killingsworth and Gilbert and other mindwandering studies thus far have not assessed distraction by irrelevant external stimuli and thus their results are restricted to the relationship of mindwandering and mood. However, as mentioned above, Forster and Lavie $(2009 ; 2014)$ have advanced the hypothesis that mindwandering is a manifestation of a more general susceptibility to irrelevant distractions, whether from internal TUT or external distractions. This raises the question as to whether the same relationships that have been noted between mindwandering and the wide range of healthy mood levels (including happiness) would be present for external distractions. We therefore set out to investigate the relationship between irrelevant external distraction and mindwandering, while also examining the associations between mindwandering, irrelevant external distractions and mood. We sought to research these in daily life experiences, which present more sources of external distraction than those in the laboratory.

Importantly, when it comes to assessing external distraction it is necessary to avoid using a sampling method that might bias the distraction report (e.g. by either being itself a source of distraction, or by being directly related to a potential source of distraction). Many studies which have previously investigated mindwandering and/or mood in everyday life have done so using experience sampling (e.g. Franklin et al., 2013; Franklin et al., 2014; Kane et al., 2017; Kane et al., 2007; Killingsworth \& Gilbert, 2010; McVay et al., 2009; Ottaviani \& Couyoumdjian, 2013; Poerio, Totterdell \& Miles, 2013; Song \& Wang, 2012). Experience sampling methods involve probing the content of participants' ongoing experiences at repeated intervals throughout the test period. Questions are generally delivered through an electronic device, for example through palm pilots/handheld personal assistants (Franklin et al., 2013; 2014; Kane et al., 2007; 2017), or to the participant's mobile phone through an application (Killingsworth and Gilbert, 2010; Ottaviani \& Couyoumdjian, 2013; 


\section{Attention, Mindwandering, and Mood}

Poerio, Totterdell \& Miles, 2013) or text messaging (Song \& Wang, 2012). While the use of these devices allows researchers to randomly sample multiple daily life experiences per person, the measure of external distraction with technological devices such as mobile phones and tablets precludes an unbiased assessment of irrelevant distraction. Mobile phones and other devices such as tablets are known to be a prevalent source of distraction (Oulasvirta, Rattenbury, Ma \& Raita, 2011; Glass \& Kang, 2018; Kuznekoff \& Titsworth, 2013) which can produce enhanced attentional responses, comparable in magnitude to stimuli of personal significance (such as hearing one's own name; Roye, Jacobsen \& Schröger, 2007). We aimed to include external distraction by mobile phones or tablets as one potential source of distraction in our study. To achieve an unbiased measure of mobile phone distraction we therefore avoided any experience sampling device and instead assessed participants with an experimenter approaching them in everyday life locations, requesting them to fill in a short paper-based questionnaire of their recent experience of mindwandering, distraction and happiness (as described in detail in the method section). In addition, investigating distraction and mindwandering in daily life provides the opportunity to assess the impact of social interaction on the relationship of mindwandering and external distraction both to each other and to happiness, a topic that has so far remained rather understudied (c.f. Kane et al., 2017; in the case of mindwandering and external distraction). We thus included an assessment of whether people were alone or engaging in a social activity in the present research.

\section{Study 1}

\subsection{Materials and method}

\subsubsection{Participants.}

Using opportunity sampling, we aimed to obtain data from a minimum of 390 participants (and no less than 50 in each city or town) in order to achieve sufficient power to detect small 


\section{Attention, Mindwandering, and Mood}

effect sizes at the level of single predictors (Harris, 2001), given the 13 study predictors in our planned regression analyses. This resulted in a final sample of 459 unpaid participants (188 males) aged between $13-79$ years (mean age $=31.7$ years, $S D=15.53$ ) that agreed to participate. No regression analysis was run prior to the end of data collection. The research was approved by the University College London research-ethics committee. Seventeen participants were discarded due to incomplete information.

\subsubsection{Procedure}

Participants were recruited from a variety of public locations in the UK cities and towns of London (central) (population size 1,525,000, average income £45,250), Birmingham $(1,124,600, £ 23,344)$, Leicester $(348,300, £ 20,956)$, Brighton $(289,200, £ 21,788)$, Walsall $(278,700, £ 19,500)$ and St Albans $(146,300, £ 18,928)$ (Office for National Statistics, 2015; 2017). Population size and regional average income were considered because these have been shown to relate to levels of happiness (e.g. Diener, Sandvik, Seidlitz \& Diener., 1993; Nguyen et al., 2016). In each location, sampling took place during daylight hours. Sampling occurred across all days of the week (including weekends). Participants were approached individually by an experimenter when engaging in a variety of everyday activities and contexts (including both outdoor and indoor), such as cafés, pubs, parks and gardens, shopping centers, streets, and transport hubs (e.g. train stations), and asked if they would consent to complete a survey on their current experiences. If they consented to participate in the study, they were then asked to complete a paper-based questionnaire designed to measure their recent experiences of distraction. In the case of participants who were seen to be engaging in a social activity with other people prior to the completion of the questionnaire, the experimenter ensured that peers could not view questionnaire responses from the participant. Participants first reported how long they had been in the location in response to 


\section{Attention, Mindwandering, and Mood}

the question: 'How long have you been here (in minutes)?' They then rated how often and for how long over this time period their attention was diverted away from their main focus to different task-irrelevant distractions, in response to the question 'Over this time, how often and for how long (in minutes) did you divert your attention from your main focus by attending to [distraction source]'. The distraction sources were: 'Your mobile phone (or tablet)', 'Advertising', 'Vehicles', 'Construction noise', 'Strangers', 'Background music', 'Animals', and 'Unrelated thoughts (mindwandering)'. Following this, participants rated their current level of happiness on a scale of 1 (extremely unhappy) to 100 (extremely happy). Finally, respondents reported their age, gender, and current state of wellness (by responding 'yes' or 'no' to the question 'Are you currently well (health wise)?').

To ensure that only attention diversions from the main focus (as phrased in their question) of activity were considered we only analysed reports of distractions up to a maximum of $50 \%$ of their 'time here'. It was assumed, however, that distractions could be experienced in parallel (i.e. that more than one source of distraction could be experienced at the same time). As a result, values of the 'total distraction duration' experienced by a participant could exceed their 'time here' figure. Whilst participants provided reports on both the frequency and duration of distractions they were experiencing, 'duration' provided a more continuous measure and was also found to be much more internally consistent than 'frequency' (Cronbach's alpha $=.735$ vs .248$)$, so duration measures alone were taken forward for subsequent analysis.

\subsection{Results}

Participants reported an average time of 36.2 minutes $(\mathrm{SD}=47.6$, mode $=30)$ of being engaged in their current activity at the sampling location. 23 participants (5\% of the sample) 


\section{Attention, Mindwandering, and Mood}

reported feeling currently unwell. 315 (71\% of the sample) reported being engaged in a social activity, together with friends, family or colleagues. The remainder of the sample reported being alone, whilst reading, shopping or walking, amongst other activities. Table 1 displays descriptive statistics for all variables of interest in the study. The most frequently reported distractions (strangers, mindwandering, mobile phones and background music) were all approximately normally distributed with values of skewness and kurtosis below widely accepted values (i.e. skewness $<3$, kurtosis $<10$; see Kline, 2015). Some of the more infrequently reported distraction sources showed a strongly positively skewed distribution, as might perhaps be expected from distraction sources which are rarer in general, but which might still cause significant disruption on occasions when they are present. Mean happiness (out of 100) was $75.1(\mathrm{SD}=20.2$, Range $=0-100)$, meaning that our sample reported slightly higher mean happiness than the UK average (UK mean in the World Happiness Report 2017 $=68.2, \mathrm{SD}=16.3$; Helliwell, Layard \& Sachs, 2017).

Table 1. Descriptive statistics for all measures of interest

\begin{tabular}{|c|c|c|c|c|c|}
\hline Age & $\begin{array}{c}\text { \% } \\
\text { reporting }\end{array}$ & Mean & St Dev & Skewness & Kurtosis \\
\hline Happiness & & 31.82 & 15.37 & 0.96 & -0.15 \\
\hline Mobile device & 78 & 17.03 & 18.14 & 0.85 & -0.76 \\
\hline Adverts & 56 & 7.85 & 13.24 & 2.09 & 3.50 \\
\hline Vehicles & 43 & 4.97 & 10.85 & 2.92 & 8.26 \\
\hline $\begin{array}{c}\text { Strangers } \\
\text { Background }\end{array}$ & 86 & 15.60 & 17.27 & 1.04 & -0.36 \\
\hline Music & 55 & 10.85 & 16.33 & 1.51 & 0.93 \\
\hline \begin{tabular}{c} 
Animals \\
\hline
\end{tabular} & 22 & 2.87 & 8.56 & 4.10 & 17.71 \\
\hline
\end{tabular}




\begin{tabular}{|c|c|c|c|c|c|}
\hline $\begin{array}{c}\text { Construction } \\
\text { noise }\end{array}$ & 31 & 3.67 & 9.74 & 3.37 & 11.47 \\
\hline Mindwandering & 87 & 18.45 & 17.33 & 0.75 & -0.82 \\
\hline
\end{tabular}

Table 1. Happiness was measured on a scale of 0-100. All mean distraction figures are expressed as percentage duration of the total activity duration. '\% reporting' represents the percentage of the sample who reported any level of distraction from the source.

The three most prevalent categories of reported distraction were mindwandering, mobile phones and strangers (we note however that the modal duration reported for each of the external distraction categories was $0 \%$ while for mindwandering it was $10 \%$ of the duration). In order to ensure that the experimenter did not introduce bias in the reporting of the 'Stranger' category (since the experimenter could potentially be classified as a distraction from a Stranger - indeed 4/442 of the sample noted this to the experimenters), all analyses reported below for Experiment 1 were repeated omitting the category of 'Strangers'. All significant relationships reported below remained significant when this category was omitted. Reports of mindwandering duration (18\%) are broadly comparable, if in the lower regions, to estimates of mindwandering rates in previous studies from both the laboratory and everyday life (which have ranged between $10 \%$ and 50\%; e.g. Kane et al., 2007; Killingsworth and Gilbert, 2010; Song \& Wang, 2012; Smallwood, McSpadden, \& Schooler, 2008; Szpunar, Khan \& Schacter, 2013).

\subsubsection{Zero-order correlations}

A correlation matrix for all variables of interest can be seen in Table 2. Significant negative correlations with age were found for all the distractor sources. This is consistent with previous research which has suggested that experiences of both distraction and mindwandering may be affected by age (e.g. Cohen et al, 2016; Maillet et al, 2018; Olesen, 
Attention, Mindwandering, and Mood

Maconveanu, Tegnér \& Klingberg, 2006; Stawarczyk et al., 2014). Age was therefore included as a control variable in all the follow-up regression analyses. 
Attention, Mindwandering, and Mood

Table 2. Correlation matrix for all variables

\begin{tabular}{|c|c|c|c|c|c|c|c|c|c|c|c|c|}
\hline & 1 & 2 & 3 & 4 & 5 & 6 & 7 & 8 & 9 & 10 & 11 & 12 \\
\hline 1. Age & & & & & & & & & & & & \\
\hline 2. Wellness & .03 & & & & & & & & & & & \\
\hline 3. Happiness & .02 & $-.21^{* *}$ & & & & & & & & & & \\
\hline 4. City size & $-.12^{*}$ & -.08 & .01 & & & & & & & & & \\
\hline 5 City income & $-.20^{* *}$ & $-.10^{*}$ & .03 & $.24^{* *}$ & & & & & & & & \\
\hline 6. Mobile phones & $-.23^{* *}$ & -.01 & $-.14^{* *}$ & $.12^{* *}$ & .04 & & & & & & & \\
\hline 7. Adverts & $-.14^{* *}$ & .04 & -.08 & .03 & .04 & $.24^{* *}$ & & & & & & \\
\hline 8. Vehicles & $-.18^{* *}$ & .05 & .03 & -.04 & -.01 & $.22^{* *}$ & $.31^{* *}$ & & & & & \\
\hline 9. Strangers & $-.16^{* *}$ & .01 & -.07 & $.11^{*}$ & $.20^{* *}$ & $.23^{* *}$ & $.34^{* *}$ & $.26^{* *}$ & & & & \\
\hline 10. B'ground Music & $-.21^{* *}$ & .03 & -.01 & -.07 & $.09^{*}$ & $.27^{* *}$ & $.43^{* *}$ & $.34^{* *}$ & $.44^{* * *}$ & & & \\
\hline 11. Animals & $-.12^{*}$ & -.07 & .08 & .05 & $.18^{* *}$ & $.16^{* *}$ & $.25^{* *}$ & $.27^{* *}$ & $.21^{* *}$ & $.29^{* *}$ & & \\
\hline $\begin{array}{l}\text { 12. Construction } \\
\text { noise }\end{array}$ & $-.14^{* *}$ & .07 & -.04 & -.06 & .02 & $.24^{* *}$ & $.27^{* *}$ & $.49^{* *}$ & $.28^{* *}$ & $.37^{* *}$ & $.30^{* *}$ & \\
\hline 13. Mindwandering & $-.21^{* *}$ & -.02 & $-.13^{* *}$ & .06 & .09 & $.29^{* *}$ & $.37^{* *}$ & $.27^{* *}$ & $.42^{* *}$ & $.30^{* *}$ & $.22^{* *}$ & $.22^{* *}$ \\
\hline
\end{tabular}




\section{Attention, Mindwandering, and Mood}

In addition, the duration of distraction reported for the different sources were all significantly correlated. Notably, mindwandering duration was significantly positively correlated with each of our measured external distractions.

\subsubsection{Underlying structure of mindwandering and external distraction}

To further investigate the structure and relationship between our distraction measures, an exploratory factor analysis (EFA) was conducted. EFA using a principal-axis factor extraction was used to analyse the factor structure of the distraction sources. For interpretation of the factors (and given that we had already demonstrated that the factors were correlated with one another) an oblique (direct oblimin) rotation was used. The KeyserMeyer-Olkin measure of sampling adequacy indicated that the sample was adequate $(\mathrm{KMO}=$ $.831)$. Bartlett's test for sphericity was significant $\left(\mathrm{X}^{2}(28)=683.48, \mathrm{p}<.001\right)$ suggesting that there were sufficient inter-item correlations for EFA. Only one factor showed an Eigenvalue of greater than 1 and inspection of the scree plot (see Figure 1) revealed a clear inflexion after one factor. This factor accounted for $38.69 \%$ of the overall variance.

All sources of distraction, including mindwandering loaded significantly onto the first factor (see Table 3) and were not only above the critical significance value for a sample size of $n=\sim 400(0.26)$ but also above the 0.4 practical significance loading value (e.g. Stevens, 2012). The results of the factor analysis thus suggest that participant reports of both mindwandering and distraction from external sources are best explained by a single underlying construct as predicted from our 'state of reduced attention focus' hypothesis.

Figure 1. Scree Plot for EFA of distraction sources

Table 3. Component loadings onto single factor 


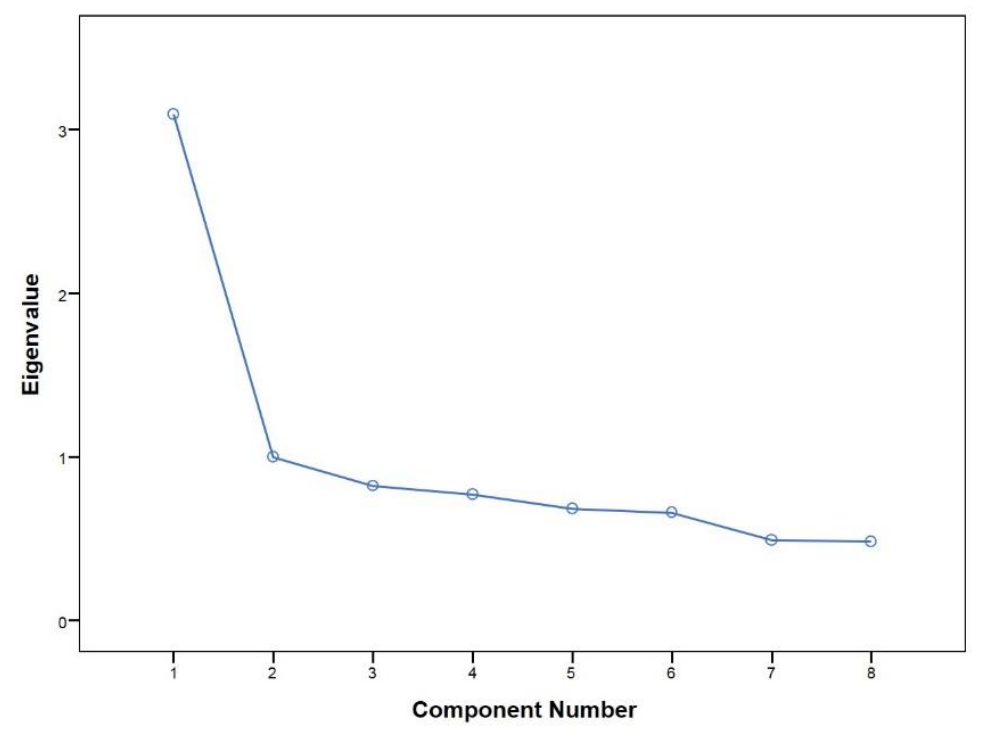

than 1 and a clear inflexion after one factor.

\begin{tabular}{|l|l|}
\hline \multicolumn{2}{|c|}{$\begin{array}{c}\text { Table 3. Component } \\
\text { loadings onto single factor }\end{array}$} \\
\hline Distraction source & Loading \\
\hline Background Music & 0.66 \\
\hline Adverts & 0.58 \\
\hline Strangers & 0.58 \\
\hline Construction noise & 0.57 \\
\hline Vehicles & 0.57 \\
\hline Mindwandering & 0.54 \\
\hline Animals & 0.44 \\
\hline Mobile device & 0.42 \\
\hline
\end{tabular}

Figure 1. Scree plot showing a single factor with an Eigenvalue of greater

As we had only a single measure of mindwandering, compared to multiple measures of external distraction, it is possible that mindwandering was included in the distraction factor simply because there were no other mindwandering measures to pull it into a separate factor. In other words, rather than mindwandering and distraction genuinely reflecting one underlying factor (of attention failure) one could perhaps argue that this is just a result due to the structure of our data. On this alternative account a similar effect would be expected to occur in the case of any other single measure which correlated with all distractors. We therefore created a second EFA in which we also included age (another single measure variable which correlated with all distractors, but was not expected to be part of the same latent factor as distraction). In this second EFA model age was not incorporated into a single factor. Instead, a two factor solution was produced with age loading only weakly onto both factors (Factor 1: -.306; Factor 2: -.231), below the value for practical significance. Thus our data was sensitive to reveal more than one factor even in the absence of multiple measures of the mindwandering variable, suggesting the alternative account is an unlikely explanation of these findings 


\section{Attention, Mindwandering, and Mood}

\subsubsection{Predicting mindwandering from external distraction}

In addition, to assess whether mindwandering can be directly predicted from levels of external distraction when background variables are controlled, we conducted a hierarchical multiple regression (Table 4). Model 1 explained a significant portion of variance in mindwandering. Of the background variables in model 1 only age was a significant predictor of mindwandering: older respondents showed reduced rates of mindwandering, consistent with previous reports (e.g. Frank, Nara, Zavagnin, Touron \& Kane, 2015; Jackson \& Balota, 2012; Krawietz, Tamplin \& Radvansky, 2012; McVay, Meier, Touron \& Kane, 2013).

Happiness was included as a control variable in model 2, with external distractions in model 3.

Table 4 - Summary of the hierarchical regression analysis for variables predicting mindwandering

\begin{tabular}{|c|c|c|c|c|c|c|}
\hline & \multicolumn{2}{|c|}{$\begin{array}{c}\text { Model } 1 \text { - } \\
\text { Background } \\
\text { variables }\end{array}$} & \multicolumn{2}{|c|}{ Model 2 - Happiness } & \multicolumn{2}{|c|}{$\begin{array}{l}\text { Model } 3 \text { - } \\
\text { Irrelevant } \\
\text { distractor } \\
\text { variables }\end{array}$} \\
\hline & $\beta$ & $\mathrm{t}$ & $\beta$ & $\mathrm{t}$ & $\beta$ & $\mathrm{t}$ \\
\hline Wellness & 0.01 & 0.21 & -0.02 & -0.34 & -0.03 & -0.67 \\
\hline Gender & 0.02 & 0.36 & 0.02 & 0.31 & -0.03 & -0.64 \\
\hline Age & -0.20 & $-4.05 * * *$ & -0.19 & $-3.99 * * *$ & -0.09 & $-1.98 *$ \\
\hline City size & 0.01 & 0.21 & 0.01 & 0.20 & -0.01 & -0.30 \\
\hline City income & 0.04 & 0.88 & 0.05 & 0.95 & -0.00 & -0.06 \\
\hline Happiness & & & -0.12 & $-2.57 *$ & -0.08 & -1.92 \\
\hline Mobile device & & & & & 0.13 & $2.82 * *$ \\
\hline Adverts & & & & & 0.17 & $3.53 * * *$ \\
\hline
\end{tabular}


Table 4 - Summary of the hierarchical regression analysis for variables predicting mindwandering

\begin{tabular}{|c|c|c|c|c|c|c|}
\hline & \multicolumn{2}{|c|}{$\begin{array}{c}\text { Model } 1 \text { - } \\
\text { Background } \\
\text { variables }\end{array}$} & \multicolumn{2}{|c|}{ Model 2 - Happiness } & \multicolumn{2}{|c|}{$\begin{array}{l}\text { Model } 3 \text { - } \\
\text { Irrelevant } \\
\text { distractor } \\
\text { variables }\end{array}$} \\
\hline & $\beta$ & $\mathrm{t}$ & $\beta$ & $\mathrm{t}$ & $\beta$ & $\mathrm{t}$ \\
\hline Vehicles & & & & & 0.09 & 1.84 \\
\hline Strangers & & & & & 0.28 & $5.77 * * *$ \\
\hline Background music & & & & & 0.01 & 0.18 \\
\hline Animals & & & & & 0.06 & 1.34 \\
\hline Construction noise & & & & & 0.01 & 0.14 \\
\hline & $\begin{array}{c}\text { Adjusted } \\
\mathbf{R}^{2}\end{array}$ & $\mathbf{F}$ & $\begin{array}{l}\text { Adjusted } \\
\mathbf{R}^{2}\end{array}$ & $\mathbf{F}$ & $\begin{array}{c}\text { Adjusted } \\
\mathbf{R}^{2}\end{array}$ & $\mathbf{F}$ \\
\hline Model Statistics & 0.04 & $4.14 * *$ & 0.05 & $6.58^{*}$ & 0.27 & $18.98^{* *}$ \\
\hline
\end{tabular}

Table 4. $\beta=$ Beta, the standardised regression coefficient; Adjusted $\mathrm{R}^{2}$ significance levels are for $\mathrm{R}^{2}$ change F-tests

$* \mathrm{p}<.05 * * \mathrm{p}<.01 * * * \mathrm{p}<.001$

Model 3 explained a significant portion of variance in mindwandering and three distraction types significantly explained a unique source of variance in mindwandering: strangers, adverts and mobile phone use. Thus, mindwandering can be uniquely predicted from the level of external distractions, and this is not driven by any mediating background variables or level of happiness.

Given that our measure involved the retrospective reporting of attention lapses, it was important to establish that the results were not confined to any memory recall strategies or biases, which would be more likely to occur for participants reporting longer periods of time on their current activity. We therefore analysed correlations between mindwandering and 


\section{Attention, Mindwandering, and Mood}

external distraction in participants who reported having been in the sampling location and engaged in their current activity for 5 minutes or less $(n=45)$. These were all of comparable size or slightly lower than the full dataset (mobile devices $\mathrm{R}=.22$; adverts $\mathrm{R}=.21$; vehicles $\mathrm{R}=.27$; strangers $\mathrm{R}=.24$; background music $\mathrm{R}=.21$; animals $\mathrm{R}=.14$; construction $\mathrm{R}=$ .18). This suggests that our findings regarding the relationship between distraction and mindwandering apply to short durations (which should suffer less from any recall strategies and biases) as well as longer ones.

\subsubsection{Distraction, mindwandering and mood}

The zero order correlations showed that mindwandering was significantly negatively correlated with happiness $(\mathrm{R}=-.126, \mathrm{p}=.008$; see Table 2$)$ in replication of Killingsworth and Gilbert's (2010) results. A novel finding was that distraction from mobile phones was also significantly negatively correlated with levels of happiness $(\mathrm{R}=-.138, \mathrm{p}=.004$; Table 2). No other individual distractors displayed significant correlations with happiness.

A hierarchical regression examined whether distraction levels could predict happiness when controlling for background variables known to be associated with happiness levels (age, gender, wellness, city size/population density, and regional average income) which were entered into model 1 of the regression model (see Table 5). Model 2 consisted of the proportional time distracted by the various environmental distractions listed in the questionnaire. Model 3 included the interaction terms between age, sampling location and wellness and the individual distractor sources. No interaction terms were significant, so they were omitted from Table 5, as well as subsequent analyses. 
Table 5 - Summary of hierarchical regression analysis for variables predicting happiness

\begin{tabular}{|c|c|c|c|c|}
\hline & \multicolumn{2}{|c|}{$\begin{array}{c}\text { Model } 1 \text { - Background } \\
\text { variables }\end{array}$} & \multicolumn{2}{|c|}{$\begin{array}{l}\text { Model } 2 \text { - Distractor } \\
\text { variables }\end{array}$} \\
\hline & $\beta$ & $\mathrm{t}$ & $\beta$ & $\mathrm{t}$ \\
\hline Wellness & -0.21 & $-4.47 * * *$ & -0.20 & $-4.31 * * *$ \\
\hline Gender & -0.02 & -0.45 & -0.02 & -0.37 \\
\hline Age & 0.03 & 0.63 & 0.000 & 0.00 \\
\hline City size & -0.00 & -0.06 & 0.02 & 0.42 \\
\hline City income & 0.03 & 0.55 & 0.01 & 0.24 \\
\hline Mobile device & & & -0.13 & $-2.50 *$ \\
\hline Adverts & & & -0.06 & -1.00 \\
\hline Vehicles & & & 0.09 & 1.55 \\
\hline Strangers & & & -0.01 & -0.27 \\
\hline Background music & & & 0.06 & 0.98 \\
\hline Animals & & & 0.10 & $2.00 *$ \\
\hline Construction noise & & & -0.06 & -1.11 \\
\hline \multirow[t]{2}{*}{ Mindwandering } & & & -0.11 & $-2.02 *$ \\
\hline & $\begin{array}{c}\text { Adjusted } \\
\mathbf{R}^{2}\end{array}$ & $\mathbf{F}$ & $\begin{array}{c}\text { Adjusted } \\
\mathbf{R}^{\mathbf{2}}\end{array}$ & $\mathbf{F}$ \\
\hline Model Statistics & 0.04 & $4.24 * *$ & 0.07 & $2.67 * *$ \\
\hline
\end{tabular}

Table 5. $\beta=$ Beta, the standardised regression coefficient; Adjusted $\mathrm{R}^{2}$ significance levels are for $\mathrm{R}^{2}$ change F-tests. ${ }^{*} \mathrm{p}<.05$ $* * \mathrm{p}<.01 * * * \mathrm{p}<.001$

Model 1 explained a significant portion of variance in happiness ratings. Of the background variables, wellness was a significant predictor of happiness. No other background variable was found to be significantly associated with happiness. Model 2 explained a significant portion of variance in happiness ratings, demonstrating that distraction overall is correlated with happiness, after controlling for background variables. In Model 2, three distractions also explained a significant amount of unique variance in happiness: distraction from mobile phones, animals and mindwandering. As expected, mobile phone 


\section{Attention, Mindwandering, and Mood}

distraction and mindwandering both negatively predicted happiness ratings. In contrast, distraction by animals was unexpectedly correlated with higher happiness levels.

An analysis of participants engaged in their current activity for 5 minutes or less $(n=$ 45) showed that zero order correlations between happiness and significant distraction and mindwandering sources were of comparable magnitude to the full dataset (mobile devices $\mathrm{R}$ $=-.204$; mindwandering $\mathrm{R}=-.117$ ). This suggests that our findings regarding relationships to happiness apply to short durations (which should suffer less from any reduced time estimation ability) as well as longer ones.

\subsubsection{Social engagement}

Relatively few studies investigating attention states and mood in everyday life have investigated the effect of social engagement. In an experience sampling study, Kane et al., (2017) found that mindwandering rates were unaffected by whether participants reported being alone or with others. However, it is not clear what such a finding might mean for the relationship to external distractions and to happiness. Killingsworth and Gilbert (2010), who assessed both mindwandering and happiness, did not report an analysis of the relationship as a function of social engagement. In our sample, 315 participants reported being engaged in a social activity, whereas the remainder (127) reported being alone. In both groups, mindwandering reports positively correlated with all external distractions (Table 6), however the magnitude of the correlations varied between groups, with lone participants reporting slightly weaker relationships between mindwandering and some external distractions (such as adverts, background music and construction noise) than those who reported engaging with others. 
Table 6. Correlations for mindwandering with external distractors, split by social engagement

\begin{tabular}{|c|c|c|c|c|c|c|c|}
\hline & $\begin{array}{c}\text { Mobile } \\
\text { device }\end{array}$ & $\begin{array}{c}\text { Adver } \\
\text { ts }\end{array}$ & $\begin{array}{c}\text { Vehicl } \\
\text { es }\end{array}$ & $\begin{array}{c}\text { Stran } \\
\text { gers }\end{array}$ & $\begin{array}{c}\text { B'groun } \\
\text { d Music }\end{array}$ & $\begin{array}{c}\text { Anima } \\
\text { ls }\end{array}$ & $\begin{array}{c}\text { Construc } \\
\text { tion }\end{array}$ \\
\hline Alone & $.28^{* *}$ & $.26^{* *}$ & $.30^{* *}$ & $.45^{* *}$ & .16 & .15 & .07 \\
\hline Social engagement & $.27^{* *}$ & $.42^{* *}$ & $.26^{* *}$ & $.42^{* *}$ & $.38^{* *}$ & $.26^{* *}$ & $.30^{* *}$ \\
\hline
\end{tabular}

Table 6. The Pearson Correlation Coefficient is shown. ${ }^{*} \mathrm{p}<0.05 * * \mathrm{p}<0.01$

We next compared distraction, mindwandering and happiness reports between participants who were alone when sampled and those who reported being engaged in a social activity. Lone participants reported being less happy (alone $M=70.67$, social engagement $M$ $=76.85, \mathrm{t}(440)=-2.933, \mathrm{p}=.002)$ and also more distracted by both mindwandering (alone $\mathrm{M}$ $=22.09$, social engagement $\mathrm{M}=16.56, \mathrm{t}(440)=3.076, \mathrm{p}=.004$; in contrast to Kane et al., 2017) and mobile phones (alone $M=22.52$, social engagement $M=14.89, t(440)=4.053, p$ $<.001)$. No other distractions reached Bonferroni corrected significance $(\alpha=.006$; all $\mathrm{t}<1.3$, all $\mathrm{p}>0.15)$

We performed the same hierarchical regression model to predict happiness as reported in Table 5, but with the addition in Model 2 of a 'social engagement' variable, which coded whether the participant was alone or engaged in a social activity. Distractor reports were moved to Model 3. The results can be seen in Table 7.

Table 7 - Summary of hierarchical regression analysis for variables predicting happiness including social engagement

\begin{tabular}{c|c|c|}
$\begin{array}{c}\text { Model 1 - } \\
\text { Background } \\
\text { variables }\end{array}$ & $\begin{array}{c}\text { Model 2 - Social } \\
\text { engagement }\end{array}$ & $\begin{array}{c}\text { Model 3 - Distractor } \\
\text { variables }\end{array}$ \\
\hline
\end{tabular}


Attention, Mindwandering, and Mood

\begin{tabular}{|c|c|c|c|c|c|c|} 
& $\mathrm{B}$ & $\mathrm{t}$ & $\beta$ & $\mathrm{t}$ & $\beta$ & $\mathrm{t}$ \\
\hline Wellness & -0.21 & $-4.47^{* * *}$ & -0.21 & $-4.40^{* * *}$ & -0.20 & $-4.25^{* * *}$ \\
\hline Gender & -0.02 & -0.45 & -0.03 & -0.69 & -0.03 & -0.54 \\
\hline Age & 0.03 & 0.63 & 0.04 & 0.8 & 0.01 & 0.24 \\
\hline City size & -0.00 & -0.06 & 0.00 & 0.04 & 0.02 & 0.41 \\
\hline City income & 0.03 & 0.55 & 0.02 & 0.29 & 0.01 & 0.09 \\
\hline Social engagement & & & 0.14 & $2.89 * *$ & 0.09 & $1.92^{*}$ \\
\hline Mobile device & & & & & -0.11 & $-2.07 *$ \\
\hline Adverts & & & & & -0.05 & -0.93 \\
\hline Vehicles & & & & & 0.09 & 1.56 \\
\hline Strangers & & & & & -0.02 & -0.27 \\
\hline Background music & & & & & 0.05 & 0.89 \\
\hline Animals & & & & & 0.10 & 1.90 \\
\hline Construction noise & & & & & -0.07 & -1.29 \\
\hline Mindwandering & & & & & -0.10 & -1.73 \\
\hline & Adjusted & $\mathbf{F}$ & Adjusted & $\mathbf{F}$ & Adjusted & F \\
\hline Model Statistics & 0.04 & $4.24 * *$ & 0.05 & $8.37 * *$ & 0.07 & $2.08 *$ \\
\hline
\end{tabular}

Table 7. $\beta=$ Beta, the standardised regression coefficient; Adjusted $\mathrm{R}^{2}$ significance levels are for $\mathrm{R}^{2}$ change $\mathrm{F}$ tests. $* \mathrm{p}<.05 * * \mathrm{p}<.01 * * * \mathrm{p}<.001$

Model 3 explained a significant portion of variance in happiness ratings, demonstrating that distraction overall is correlated with happiness, after additionally controlling for social engagement. Notably, however, controlling for social engagement led to mindwandering no longer predicting a significant proportion of unique variance in happiness ratings.

Interestingly, there was a significant relationship between mindwandering and happiness in participants who were engaging with others (zero-order correlation $\mathrm{R}=-.121, \mathrm{p}=.03$ ), and no significant correlation between the two for those who were alone $(\mathrm{R}=-.084, \mathrm{p}=.346)$.

\section{Study 2}

Study 2 was carried out to test the replicability of the results of Study 1, using the same method of data collection. We calculated the minimum sample size required to assess the three main findings, firstly, the relationship between mindwandering and external 


\section{Attention, Mindwandering, and Mood}

distractions, secondly the association between distraction and happiness, and thirdly the association between mobile phones and mindwandering and reduced happiness. Based on the effect sizes for our significant findings (smallest effect size mindwandering on happiness, Cohen's $\mathrm{f}^{2}=1.235$ ) and the number of significant variables affecting results in each previous multiple regression, we calculated (using G*Power; Faul, Erdfelder, Buchner \& Lang, 2009) that 82 subjects would be sufficient to detect comparable effect sizes with a power level of 0.8. Given the smaller sample size we avoided sampling from the same wide age range sampled in Study 1 and instructed the experimenters to restrict the age of participants recruited to participants under 30 years old.

\subsection{Participants}

Using opportunity sampling, 82 participants (39 males) were recruited from a variety of locations within the central London area, in daylight hours across all days of the week (including weekends). The mean age was $16.8(\mathrm{SD}=4.41$, range 12-29).

\subsection{Results}

Participants reported an average time of 48.7 minutes $(S D=44.0$, mode $=30)$ of being engaged in their current activity at the sampling location. 2 participants $(3 \%)$ reported feeling currently unwell. 76 (92\%) of the sample reported engaging in a social activity. Descriptive statistics for all variables of interest are shown in Table 8. Once again the three most prevalent categories of reported distraction were strangers, mindwandering and mobile phones. Like in Study 1 the modal proportional duration reported for each 


\section{Attention, Mindwandering, and Mood}

of the external distraction categories was $0 \%$ while for mindwandering it considerably more (in this case $50 \%$ of the time).

Table 8. Descriptive statistics for all variables of interest - Study 2

\begin{tabular}{|c|c|c|c|c|c|}
\hline & \% reporting & Mean & St Dev & Skewness & Kurtosis \\
\hline Happiness & & 74.3 & 19.99 & -1.06 & 1.20 \\
\hline Mobile device & 78 & 16.85 & 17.83 & 0.82 & -0.76 \\
\hline Adverts & 70 & 10.3 & 14.93 & 1.73 & 1.94 \\
\hline Vehicles & 61 & 10.48 & 16.31 & 1.69 & 1.49 \\
\hline Strangers & 88 & 17.48 & 16.90 & 0.91 & -0.51 \\
\hline B'Ground Music & 68 & 11.83 & 15.97 & 1.44 & 0.83 \\
\hline Animals & 48 & 8.00 & 13.40 & 1.83 & 2.53 \\
\hline Construction noise & 45 & 6.00 & 11.94 & 2.56 & 5.97 \\
\hline Mindwandering & 87 & 19.75 & 17.55 & 0.65 & -0.95 \\
\hline
\end{tabular}

Table 8. Happiness was measured on a scale of 0-100. All mean distraction figures are expressed as percentage duration of the total activity duration. '\% reporting' represents the percentage of the sample who reported any level of distraction from the source.

\subsubsection{Zero-order correlations}

A correlation matrix for all variables of interest can be seen in Table 9. There were no significant zero order correlations between age and distraction reports. This was likely due to the more restricted age range of the sample for Study 2. With one exception (construction noise vs. mobile phones, $\mathrm{R}=0.185, \mathrm{p}=.096$ ) all distraction reports were significantly positively correlated with one another, as in Study 1 . Happiness was significantly negatively correlated with both distraction from mobile phones and mindwandering, also replicating Study 1 . In addition, distraction by adverts and background music was also significantly negatively correlated with happiness in this new sample. Unlike in Study 1, wellness was not significantly correlated with reduced happiness. However, only 2 of 82 participants in this new sample reported feeling unwell at the time of sampling, making it unlikely that such a relationship would be detected. 
Table 9. Correlation matrix for all variables in Study 2

\begin{tabular}{|c|c|c|c|c|c|c|c|c|c|c|}
\hline & 1 & 2 & 3 & 4 & 5 & 6 & 7 & 8 & 9 & 10 \\
\hline 1. Age & & & & & & & & & & \\
\hline 2. Wellness & .13 & & & & & & & & & \\
\hline 3. Happiness & -.08 & .08 & & & & & & & & \\
\hline 4. Mobile device & .07 & .14 & $-.31^{* *}$ & & & & & & & \\
\hline 5. Adverts & -.19 & .02 & $-.33^{* *}$ & $.36^{* *}$ & & & & & & \\
\hline 6. Vehicles & -.14 & .06 & -.08 & $.33^{* *}$ & $.28^{*}$ & & & & & \\
\hline $\begin{array}{l}\text { 7. B'ground } \\
\text { Music }\end{array}$ & -.17 & .05 & $-.26^{*}$ & $.47^{* *}$ & $.41^{* *}$ & $.50^{* *}$ & & & & \\
\hline 8. Animals & -.06 & .08 & .06 & $.31^{* *}$ & $.35^{* *}$ & $.44^{* *}$ & $.43^{* *}$ & & & \\
\hline 9. Strangers & -.05 & -.00 & .05 & $.22^{*}$ & $.42^{* *}$ & $.43^{* *}$ & $.54^{* *}$ & $.40^{* *}$ & & \\
\hline $\begin{array}{l}\text { 10. Construction } \\
\text { noise }\end{array}$ & -.08 & .12 & .04 & .19 & $.37^{* *}$ & $.41^{* *}$ & $.49^{* *}$ & $.50^{* *}$ & $.48^{* *}$ & \\
\hline $\begin{array}{c}11 . \\
\text { Mindwandering }\end{array}$ & .10 & .09 & $-.32^{* *}$ & $.43^{* *}$ & $.59^{* *}$ & $.25^{*}$ & $.43^{* *}$ & $.41^{* *}$ & $.43^{* *}$ & $.49^{* *}$ \\
\hline
\end{tabular}

In the same manner as Study 1, EFA using a principal-axis factor extraction and a direct oblimin rotation was used to analyse the factor structure of the distraction sources. The Keyser-Meyer-Olkin measure of sampling adequacy indicated that the sample was adequate $(\mathrm{KMO}=.842)$. Bartlett's test for sphericity was significant $\left(\mathrm{X}^{2}(28)=217.458, \mathrm{p}<.001\right)$ suggesting that there were sufficient inter-item correlations for PCA. As in Study 1, only one factor showed an Eigenvalue of greater than 1 and inspection of the scree plot (see Figure 2) revealed a clear inflexion after one factor. This factor accounted for $48.25 \%$ of the overall variance. As in Study 1 all sources of distraction loaded significantly onto the first factor (see Table 10) 


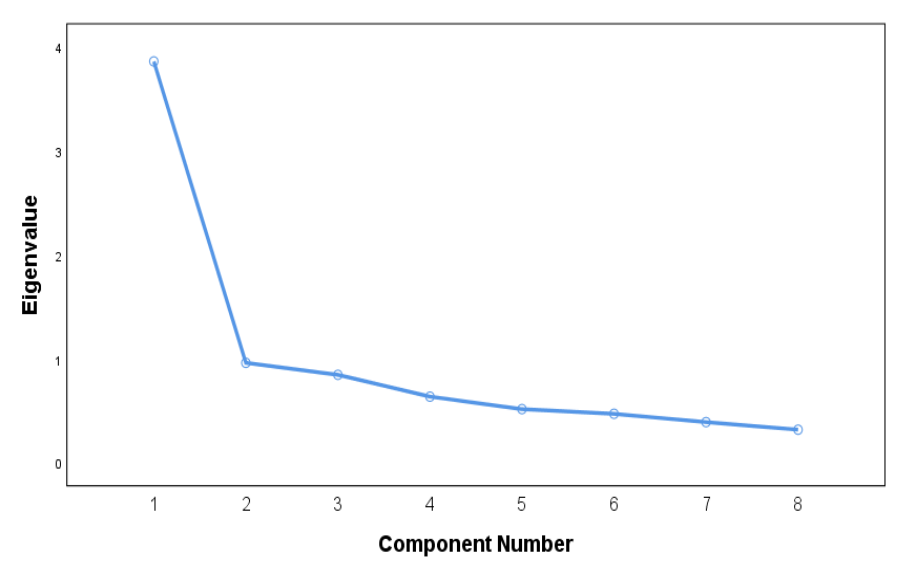

\begin{tabular}{|l|l|}
\hline \multicolumn{2}{|c|}{$\begin{array}{c}\text { Table 10. Component } \\
\text { loadings onto single factor in } \\
\text { Study } 2\end{array}$} \\
\hline Background Music & 0.74 \\
\hline Mindwandering & 0.68 \\
\hline Strangers & 0.67 \\
\hline Construction noise & 0.67 \\
\hline Animals & 0.64 \\
\hline Adverts & 0.62 \\
\hline Vehicles & 0.59 \\
\hline Mobile device & 0.51 \\
\hline
\end{tabular}

Table 10. Component loadings onto single factor in Study 2

Figure 2. Scree plot showing a single factor with an Eigenvalue of greater than 1 and a clear inflexion after one factor.

\subsubsection{Predicting mindwandering from external distraction}

As in Study 1, a hierarchical multiple regression was conducted to predict mindwandering from levels of external distraction (Table 11). Background variables (model 1) did not explain a significant portion of variance in mindwandering (unlike in Study 1).

Notably age, which was a significant predictor in Study 1, was insignificant in this model, showing that the decision to restrict the age range of participants had indeed reduced the variance attributable to this variable. Happiness was included as a control variable in model 2, with external distractions in model 3, as in Study 1. Model 3 explained a significant portion of variance in mindwandering and three distraction types significantly explained a unique source of variance in mindwandering: construction noise, adverts and mobile phone use. Thus, as in Study 1, mindwandering could be predicted from the level of external distractions. The results also replicated the finding that adverts and mobile phone distraction predicted significant unique levels of variance in the prediction of mindwandering levels, while finding that in this sample construction noise was also a predictive factor. 
Table 11 - Summary of the hierarchical regression analysis for variables predicting mindwandering in Study 2

\begin{tabular}{|c|c|c|c|c|c|c|}
\hline & \multicolumn{2}{|c|}{$\begin{array}{c}\text { Model } 1 \text { - } \\
\text { Background } \\
\text { variables }\end{array}$} & \multicolumn{2}{|c|}{$\begin{array}{l}\text { Model } 2 \text { - } \\
\text { Happiness }\end{array}$} & \multicolumn{2}{|c|}{$\begin{array}{c}\text { Model } 3 \text { - Irrelevant } \\
\text { external } \\
\text { distractions }\end{array}$} \\
\hline & $\mathrm{B}$ & $\mathrm{t}$ & $\beta$ & $\mathrm{t}$ & $\beta$ & $\mathrm{t}$ \\
\hline Wellness & 0.11 & 0.96 & 0.14 & 1.24 & 0.01 & 0.10 \\
\hline Gender & -0.16 & -1.43 & -0.16 & -1.5 & 0.04 & 0.39 \\
\hline Age & 0.13 & 1.14 & 0.10 & 0.88 & 0.15 & 1.63 \\
\hline Happiness & & & -0.29 & $-2.65^{*}$ & -0.18 & -1.90 \\
\hline Mobile device & & & & & 2.13 & $2.05^{*}$ \\
\hline Adverts & & & & & 0.26 & $2.36^{*}$ \\
\hline Vehicles & & & & & -0.09 & -0.90 \\
\hline Strangers & & & & & 0.07 & 0.62 \\
\hline Background music & & & & & 0.02 & 0.14 \\
\hline Animals & & & & & 0.15 & 1.33 \\
\hline \multirow[t]{2}{*}{ Construction noise } & & & & & 0.32 & $2.88 * *$ \\
\hline & $\begin{array}{c}\text { Adjusted } \\
\qquad \mathbf{R}^{2}\end{array}$ & $\mathbf{F}$ & $\begin{array}{l}\text { Adjusted } \\
\qquad \mathbf{R}^{2}\end{array}$ & $\mathbf{F}$ & $\begin{array}{c}\text { Adjusted } \\
\mathbf{R}^{\mathbf{2}}\end{array}$ & $\mathbf{F}$ \\
\hline Model Statistics & 0.01 & 1.22 & 0.08 & $7.03 *$ & 0.47 & $8.76^{* * *}$ \\
\hline
\end{tabular}

Table 11. $\beta=$ Beta, the standardised regression coefficient; Adjusted $\mathrm{R}^{2}$ significance levels are for $\mathrm{R}^{2}$ change $\mathrm{F}$ tests. $* \mathrm{p}<.05 * * \mathrm{p}<.01 * * * \mathrm{p}<.001$

\subsubsection{Predicting happiness from external distraction and mindwandering}

As in Study 1, a hierarchical regression examined whether distraction levels could predict happiness when controlling for background variables (see Table 12).

Table 12 - Summary of hierarchical regression analysis for variables predicting happiness in Study 2

\begin{tabular}{|c|c|c|c|c|}
\hline \multirow{2}{*}{} & \multicolumn{2}{|c|}{$\begin{array}{c}\text { Model 1 - } \\
\text { Background } \\
\text { variables }\end{array}$} & \multicolumn{2}{c|}{$\begin{array}{c}\text { Model 2 - Distractor } \\
\text { variables }\end{array}$} \\
\hline & $\beta$ & $\mathrm{t}$ & $\beta$ & $\mathrm{t}$ \\
\hline Wellness & 0.03 & 0.29 & 0.13 & 1.08 \\
\hline Gender & -0.08 & -0.67 & -0.09 & -0.78 \\
\hline Age & -0.10 & -0.85 & -0.13 & -1.17 \\
\hline
\end{tabular}




\section{Attention, Mindwandering, and Mood}

\begin{tabular}{|c|c|c|c|c|}
\hline Mobile phone & & & -0.01 & -0.05 \\
\hline Adverts & & & -0.28 & $-2.07^{*}$ \\
\hline Vehicles & & & -0.06 & -0.47 \\
\hline Strangers & & & 0.23 & 1.63 \\
\hline Background music & & & -0.30 & $-1.93^{*}$ \\
\hline Animals & & & 0.29 & $2.17^{*}$ \\
\hline Construction noise & & & 0.25 & 1.80 \\
\hline Mindwandering & & & -0.31 & $-2.03^{*}$ \\
\hline & $\begin{array}{c}\text { Adjusted } \\
\mathbf{R}^{2}\end{array}$ & $\mathbf{F}$ & $\begin{array}{c}\text { Adjusted } \\
\mathbf{R}^{2}\end{array}$ & $\mathbf{F}$ \\
\hline Model Statistics & -0.02 & 0.44 & 0.19 & $3.46^{* *}$ \\
\hline
\end{tabular}

Table 12. $\beta=$ Beta, the standardised regression coefficient; Adjusted $\mathrm{R}^{2}$ significance levels are for $\mathrm{R}^{2}$ change F-tests. *p < $.05 * * \mathrm{p}<.01 * * * \mathrm{p}<.001$

As can be seen in Table 12, Model 1 did not explain a significant portion of variance in happiness ratings and no individual variable was a significant predictor of happiness. Model 2 explained a significant portion of variance in happiness ratings, replicating the findings of Study 1 that distraction overall is correlated with happiness, after controlling for background variables. In Model 2, four distractions also explained a significant amount of unique variance in happiness. Adverts, background music and mindwandering negatively predicted happiness ratings. Distraction by animals was correlated with higher happiness levels (as in Study 1).

In summary, Study 2 was able to replicate most of the major findings of Study 1 . Rates of mindwandering were again found to be closely related to rates of external distraction, and best explained as arising from a single underlying construct. Distraction rates in general significantly predicted happiness, and mindwandering specifically and uniquely predicted lowered mood. Distraction by mobile phones was significantly correlated to reduced happiness, although this relationship was not retained in the multiple regression. In addition, the association between distraction by animals and increased happiness was also replicated. 


\section{Attention, Mindwandering, and Mood}

\section{Discussion}

The present findings demonstrated that mindwandering is significantly associated with higher levels of irrelevant distraction from a variety of external sources present in everyday life (namely, mobile phones, adverts, vehicles, strangers, background noise, animals and construction noise). Indeed the duration of irrelevant distraction reported could predict the duration of mindwandering across the two studies, including when happiness as well as wellness, age, gender, city size and regional average income were controlled for. Moreover, in both studies, the EFA produced a clear one-factor solution, onto which all sources of distraction, importantly including mindwandering, loaded significantly, thus highlighting a single underlying construct. In addition, the findings revealed that both mindwandering and mobile phone distractions were associated with reduced levels of happiness, a relationship established across a wide range of mood levels with an overall average comparable to the UK national average (though in the case of mobile phone distraction, Study 2 only replicated the zero order correlation with happiness; while this was fully replicated for the relationship of mindwandering to happiness).

Overall, the present findings support our hypothesis that the duration of mindwandering can be predicted from the duration of external distractions across a variety of different external distraction sources, consistent with our suggestion that these may be both attributed to a general state of reduced attention focus. They also extend attention research on distraction to demonstrate that the relationships between some distractions and mood can be observed even in healthy mood ranges, rather than just during low mood states (c.f. Cornblatt et al., 1989; Gohier et al., 2009). Next we discuss these research advances in more detail. 


\section{Attention, Mindwandering, and Mood}

\subsection{Irrelevant distraction and mindwandering}

A central feature of the link between mindwandering and external distraction has been identified as task-irrelevance. Forster and Lavie (2014) found that the very same distractor stimuli correlated significantly with mindwandering, when they were task-irrelevant, but not when they were task-relevant (congruent or incongruent with the target response). Measuring distractions in the rich daily life environment in the present study, specifically defined as diversions from people's main focus, allowed us to clearly examine distraction by taskirrelevant stimuli. The findings that the broad range of task-irrelevant external distraction reported were all significantly correlated with mindwandering further supports the hypothesis that task-irrelevance plays a critical role in the positive relationship of distraction and mindwandering. The findings also generalize previous research on similarities and differences between mindwandering and distraction, beyond task-irrelevant distractions reported in controlled laboratory settings (e.g. Stawarczyk et al., 2011a; 2011b; 2014), and beyond irrelevant distractions experienced during college (e.g. Unsworth et al., 2012), as well as across a wide range of ages. The findings also clarify that the relationship between mindwandering and external distractions persists in situations of engagement in social activities. Importantly, the present research extends previous research that has typically measured the frequency of mindwandering and distraction reports to address the relationship between the duration of mindwandering and distraction episodes, in further support of the hypothesis that an attention disengagement state should lead to longer durations of both types of attention failures.

The diverse distractions measured resulted in a significant variation in the average duration of distraction reported, yet all of them correlated significantly with the duration of 


\section{Attention, Mindwandering, and Mood}

mindwandering. Importantly, the strength of the relationship to mindwandering is not simply a function of reported duration. For example, in both studies the duration of distraction by 'Construction noise' was amongst the shortest of the reported distractions (4\% and 6\% on average in Study 1 and Study 2 respectively) while the duration of distraction by mobile phone reported was $17 \%$ of the time in both studies, nevertheless they were both positively correlated with mindwandering. Similarly, distraction by adverts was reported to last $8 \%$ (Study 1) and $10 \%$ (Study 2) of the time, yet this was significantly predictive of mindwandering duration in the regression model for both studies. In contrast, 'Strangers', one of the most reported distractions (in terms of both duration and the number of people reporting it in both studies) was only predictive of mindwandering rates in Study 1.

The finding of a consistent positive association of mindwandering and the different types of external distraction reported despite the large variation in the durations of different distractions is important when considering the reliance of mindwandering reports on metaawareness. Although we note that conscious awareness of being distracted is equally required for measures of both mindwandering and external distraction (given that both are based on subjective reports), one could perhaps argue that reporting mindwandering relies more on meta-awareness abilities compared to reports about being distracted from an external stimulus (for example for distractor stimuli that provoke a strong sensory sensation, e.g. a loud noise). If this were the case, an alternative account to our hypothesis of a state of reduced attention focus mediating the association of the two could be raised in terms of the awareness factor involved in subjective reports. Specifically, one could propose that the relatively lower meta-awareness of mindwandering may result in a person relying on their (sometimes clearer) awareness of being distracted by an external stimulus in their mindwandering reports. For example, a person aware that they have diverted their attention 


\section{Attention, Mindwandering, and Mood}

from their current focus to an advertising poster for a short duration might then decide to report a similarly short duration of mindwandering as well. In this case we would expect a similar average duration for mindwandering and adverts, however mindwandering duration was in fact close to double the duration reported for distraction by adverts. Neither could the sum duration of external distraction reported account for the $17 \%$ duration reported of mindwandering, given that it is both not clear how a person would sum up partly overlapping experiences of distraction and that a straight sum amounts to far longer duration than the reported duration for mindwandering. Finally, in both studies the modal duration for all external distractions was 0 , while for mindwandering the modal duration was longer $(10 \%$ in Study 1 and 50\% in Study 2), again suggesting that mindwandering reports are not being based on experiences of external distraction.

In addition, while it can be easily imagined how being distracted by some sources (such as an advert) might trigger mindwandering related to the distraction, this seems far less likely for some other of our reported distractions (e.g. construction noise). One widely accepted factor in the occurrence of mindwandering is the current concerns hypothesis (Klinger, Gregoire, \& Barta, 1973; see also Smallwood \& Schooler, 2006; McVay \& Kane, 2010), which suggests that the goals, wishes, and desires of an individual may lead to certain thoughts having greater incentive value than incoming perceptual information. Some external stimuli are more likely to tap into current concerns (e.g. advertising will often be designed to do so), whilst others are less likely to relate to the current goals and wishes etc. (e.g. strangers, construction). Despite this, the relationship persists across all of our sampled distractions. This suggests that the relationship found between duration of mindwandering and external distractions is not simply the result of mindwandering being triggered by external stimuli which relate to, and perhaps activate, current concerns. In addition, there is 


\section{Attention, Mindwandering, and Mood}

no clear reason why the duration of an external distraction should correlate significantly with the duration of any mindwandering episode that they might trigger. For example, if external distraction from construction noise were to trigger mindwandering about how the building might look when it is finally built, there seems to be little reason to suppose that a longer noise duration would lead to a longer train of thought about the finished building.

Overall, we argue that the variability in distractor stimuli, reported durations and number of people reporting each, makes it highly unlikely that their correlation with mindwandering was driven by mindwandering duration reports being based on the duration of distraction by the external stimuli. Instead the findings are suggestive of a shared mechanism of reduced attention focus leading to greater durations of both mindwandering and external distraction, although this conclusion requires a more direct investigation. An attention focus account could be strengthened in further studies by the inclusion of a separate measure of attentional focus, independent of distraction reports. This would allow for the measurement of distraction and mindwandering during different states of attention focus, and therefore the differentiation of attention lapses due to reduced attention focus, as compared to those resulting from particularly distracting environments, for example.

The EFA finding of a common factor shared with mindwandering and the diverse forms of irrelevant daily-life distractions, is also consistent with the hypothesis of a common underlying attention mechanism (see also Forster \& Lavie, 2014; 2016), and supplements the 'Executive Failure' theory of mindwandering (McVay \& Kane, 2010), in which mindwandering in daily life represents a failure to proactively sustain attention towards taskrelevant stimuli, in the same manner as external distraction. We note, however, that in the real world a state of reduced attention focus could either be due to an executive control 


\section{Attention, Mindwandering, and Mood}

failure to maintain focus on the current task or activity goal (e.g. Lavie 2000; 2010; Lavie et al. 2004), or, in some cases_could be intentional (e.g. 'allowing' one's focus to shift away during boring tasks; Seli, Risko \& Smilek, 2016). This would not represent a failure of executive control but rather setting additional task-unrelated goals (e.g. to check your mobile phone for new messages). Although we did not explicitly interrogate participants about their intention, the relationship of mindwandering and distraction was established across participants reporting being engaged in a social activity who are less likely to wish to distract themselves from their social engagement. In addition, it is notable that our findings that different types of irrelevant distraction can predict mindwandering, included both unpleasant sources of distraction (e.g. construction noise) which are unlikely to be attractive for a deliberate shift of attention, and more pleasant sources (e.g. background music), or those that can provide another task-unrelated goal (mobile phone) which may involve an intentional shift of attention. This suggests that both cases of intentional and unintentional disengagement from the current attention focus (see Seli, Carriere \& Smilek, 2014; Seli, Risko \& Smilek, 2016), share a close relationship with mindwandering.

It should be noted here that the finding that mindwandering and external distraction in everyday life can best be explained by a single underlying construct (as found in both Study 1 and Study 2), does not of course imply that these are isomorphic. Significant differences should remain between the source (being internally, versus externally, generated), the content (thoughts can be entirely abstract, while external distractions are always related to an external stimulus by definition) and the underlying neural correlates. Visual cortex regions related to distractor stimulus perception have been shown to be involved in external distraction (e.g. Rees, Frith \& Lavie, 1997; De Fockert, Rees, Frith \& Lavie, 2001); while the default mode network (DMN) is known to be associated with mindwandering (Mason et al., 2007), and 


\section{Attention, Mindwandering, and Mood}

some DMN regions (medial prefrontal cortex, the posterior cingulate cortex/precuneus, and left middle temporal gyrus) specifically show greater activity during mindwandering compared to external distraction (Stawarczyk et al., 2011b). Mindwandering has also been found to be associated with a larger pre-trial pupil dilation, compared to external distraction during a vigilance task (Unsworth \& Robison, 2016). Overall, despite these differences between mindwandering and external distraction, the correlation was found here to be consistent, and replicable, in everyday environments and during a wide variety of everyday distraction sources and activities, including social engagement.

The present results show a relationship between states of mindwandering and external distraction over relatively short timescales (mean duration was 36 minutes). It is possible, however, that the constructs may be more dissociable at general trait levels. For example, in a recent questionnaire of 'attentional style' which specifically aimed to differentiate externally and internally oriented 'attention styles' (Van Calster, D’Argembeau \& Majerus, 2018), responses to questions targeting mindwandering and external distraction loaded onto separate factors. Such a difference at a trait level could perhaps be driven by other stable factors such as working memory capacity, with which mindwandering and external distraction have also been found to sometimes display a different relationships to one another. Specifically while mindwandering frequency can be associated with higher WM capacity at least in tasks that are fairly undemanding on working memory executive control resources (Levinson, Smallwood \& Davidson, 2012), external distraction frequency has been associated with lower working memory capacity (Stawarczyk et al., 2014) in a group of young adults. We note however that the relationship of mindwandering and working memory capacity is more complex and is likely to depend on an interaction between an individual's working memory capacity and the level to which the current task places demands on working memory 


\section{Attention, Mindwandering, and Mood}

executive control resources. In tasks involving a greater demand on executive control mindwandering is also found to be associated with lower working memory capacity, potentially reflecting failures of attentional control (e.g. McVay \& Kane, 2009; 2010) similarly to external distractions (e.g. Lavie et al. 2004).

\subsection{Attention focus and Mood}

The present findings also extend into the field of mood. In Study 1, both mindwandering and task-irrelevant distraction from mobile phones were negatively associated with the level of happiness reported. This suggests that in addition to the well-documented effects on taskperformance, some failures of attention focus may have emotional repercussions. The relationship established was found across a wide range of mood, spanning both very low and very high scores (from 0-100) and with an overall healthy mood average slightly above the UK mean. The results thus suggest that the former associations between mood and susceptibility to irrelevant distractions (e.g. Gohier et al., 2009; Cornblatt et al., 1989; Mialet, Pope \& Yurgelun-Todd, 1996) or mindwandering (e.g. Deng et al., 2014; Smallwood et al., 2007, Stawarczyk, et al., 2012; Mrazek et al., 2013) established for low mood states and depression represent one end of a wider-held relationship established across the full spectrum here. The results also replicate and extend Killingsworth \& Gilbert's (2010) finding that mindwandering is associated with lower levels of happiness to a different sample, and a different experience sampling method (which allowed for the reporting of longer periods of distraction than previous research using traditional experience sampling). Importantly our results extend into the realm of external distraction, specifically task-irrelevant distraction by a mobile phone and mood. 


\section{Attention, Mindwandering, and Mood}

The findings of Study 1 were established across gender, a wide age range (from teenagers to the elderly), and in a variety of everyday activities and contexts (including both outdoor and indoor activities), in six different UK cities and towns of varying population size and regional income. We note that an individual's state of wellness was found to be a significant predictor of happiness (replicating findings of Røysamb, Tambs, ReichbornKjennerud, Neale \& Harris, 2003), however our findings held when wellness as well as all of the aforementioned background variables were specifically controlled for. Study 2 replicated the negative correlations with happiness for mindwandering and mobile devices, though once variance shared with control variables and all other distractions was accounted for in a multiple regression, mobile devices were no longer associated with reduced levels of happiness. Instead, distractions from adverts and background music significantly predicted reduced happiness. The weaker relationship between mobile phone as a unique predictor of happiness in Study 2 might be attributed to the younger age of the study sample, future research specifically focusing on age, distraction and happiness would be important to establish the role of age in this relationship.

Interestingly, in an exception, distraction by 'animals' ("e.g. dogs and birds" were mentioned as examples in the question item) was associated with increased levels of happiness, though only when variables such as wellness were controlled for. Interaction with animals has been previously established to increase the sense of well-being (e.g. Souter \& Miller, 2007), however such interactions were intentional, whereas here they were identified as task-irrelevant distractions. In both studies, however, animals did not display a zero-order correlation with happiness, and were also among the least reported of all distractions $(2.85 \%$ of the duration reported in Study 1; mindwandering and mobile phones were reported around six times this amount; see Table 2), and this may have contributed to the lack of negative 


\section{Attention, Mindwandering, and Mood}

impact. In other words, it is plausible that distraction by animals for a substantial duration of time would have reversed, or diminished, the relationship.

Finally, with respect to any causal inference regarding the relationship between attention focus and mood, the current findings are open to two plausible interpretations. Previous research on the effects of induced low levels of mood supports a potential interpretation in terms of lower mood causing vulnerability to distraction (Pacheco-Unguetti \& Parmentier, 2013) and mindwandering (Smallwood 2009, Smallwood \& O’Connor, 2011, Ruby, Smallwood, Engen \& Singer, 2013). However, Stawarczyk, Majerus \& D’Argembeau (2013) demonstrated that manipulations of induced negative mood can result in increased mindwandering, which in turn predicted subsequent negative affect (see also Poerio et al., 2013) thus suggesting a bidirectional relationship. It remains unclear whether these effects extend to the full range of mood, for example whether induced positive mood would have similar effects on both mindwandering and mobile phone distractions. These are interesting topics for further research.

An alternative causal interpretation comes from Killingsworth and Gilbert (2010) findings that in a time-lag analysis on their repeated measures data (of both mindwandering and a wide range of daily life mood), happiness tended to be lower in the sampling period after, rather than before, reports of mindwandering. This suggests that mindwandering can cause - as well as maintain (as per Stawarczyk et al., 2013) - a reduced level of happiness. Our extension of the association of mindwandering and lower levels of happiness to mobile phone distractions may suggest that attention focus can play a role in creating, or at least maintaining, a higher level of happiness. This interpretation is also consistent with previous suggestions that mindfulness can induce a better sense of well-being (Brown \& Ryan, 2003). 


\section{Attention, Mindwandering, and Mood}

Future research using repeated sampling will be necessary in order to further establish the important and potentially causal relationship of attention focus and happiness.

\subsection{Social engagement}

An interesting further question raised by our data concerns the relationship between distraction, mindwandering and mood in relation to social interaction. The present findings demonstrated that social interaction is related to increased happiness, and conversely that aloneness is related to reduced happiness, in replication of previous research (e.g. Argyle, 1987; Burt, 1987; Csikszentmihalyi \& Larson, 2014; Diener, 2000; Lu, 1999). Little research however has explored whether being engaged in a social interaction has any bearing on mindwandering or distraction, and the subsequent relationship between these constructs and happiness. In one example, Kane et al., (2017) asked college students to repeatedly complete a detailed experience sampling questionnaire on the content of their off-task thoughts, as well as providing information on their current efforts to concentrate, activity and emotional context. They found that social interaction (vs. aloneness) was not associated with a change in the level of mindwandering, while in the present study social interaction was significantly associated with reduced mindwandering levels (as well as reduced durations of mobile phone distractions) in the wider population sampled. More importantly, Kane et al. did not examine whether the social context affected the relationship between mindwandering and mood or reports of external distractions. In Study 1 we found that social engagement does play a role in the relationship of mindwandering to reduced levels of happiness (mindwandering no longer predicted happiness in a regression model when social engagement was controlled for), but mobile phone distractions remained a significant predictor of happiness. These results suggest a potentially important moderator to be taken into account in future studies. 


\section{Attention, Mindwandering, and Mood}

Importantly, the relationship of mindwandering and external distractions was found across both conditions of aloneness and social interaction. This is an important extension of previous laboratory research since the nature of social engagement activity is rather different to laboratory task engagement. As mentioned earlier (in section 4.1) social interaction is likely to involve reduced likelihood of intentional mindwandering and distraction compared to during a laboratory task. Another notable difference may be in the degree of cognitive challenge provided by the focal task - a social activity such as chatting with a friend is likely to be somewhat less demanding on executive control compared to most laboratory tests of attention, while at the same time such social interaction can be more attention-engaging overall due to a higher level of interest. Reduced executive control is expected to lead to both increased mindwandering and irrelevant distractions and mindwandering, while increased demand on attention is expected to reduce both (e.g. Forster \& Lavie, 2009). Different social interactions would also involve different demand on both attention and executive control (for example work lunch with your boss is likely to increase the demand on executive control). The present findings that the relationship between mindwandering and external distractions persists in social engagement despite this great variability in the demands on cognitive functions provides an important generalisation of previous research.

\subsection{Frequency versus duration in the measurement of attention focus}

We note one important difference between this study and most previous research into attention (as well as mood) is that participants here provided a measure of duration of distraction and mindwandering, rather than frequency. Whilst a valuable research tool, probe questions which collect frequency of responses are limited in two ways. Firstly, the framing of most probe questions does not allow for any information to be gathered regarding the 


\section{Attention, Mindwandering, and Mood}

inter-probe interval, which can often be as long as a few hours (see Weinstein, 2017 for a review). Two consecutive probe reports of mindwandering or distraction may therefore represent either two separate short-lived events or one prolonged task-disengaged episode (a state which might be especially relevant to our current research question regarding associations with mood). Secondly, it is unlikely that mindwandering and external distraction will be reported together in any one probe question. This may either be because immediate reporting of concurrent mindwandering and external distraction is less likely due to 'perceptual decoupling' during the very instant of mindwandering (see e.g. Smallwood, 2013; Smallwood \& Schooler, 2015), or because response options explicitly preclude this (e.g. Stawarczyk, et al., 2011a; Stawarczyk, et al., 2011b; Stawarczyk et al., 2014, Unsworth \& McMillan, 2014; Unsworth \& Robison, 2016). This makes it unclear how mindwandering and external distraction relate to one another over time, for example whether within a particular period of time increased duration spent mindwandering might be associated with more or less time of also being distracted by external stimuli.

The results presented here provide two new pieces of evidence in this regard. Firstly, longer proportional durations (of the total task or activity) of mindwandering are positively correlated with longer proportional durations of external distraction. This provides a new insight into the relationship between the duration of periods of distraction and mindwandering in everyday life, demonstrating that a state in which external distraction is prevalent is also likely to involve increased mindwandering. Secondly, the results link longer proportional durations of distraction and mindwandering to reduced mood. These findings complement the results of previous investigations which have found a relationship between the frequency of mindwandering and mood (Killingsworth \& Gilbert, 2010; Franklin et al., 


\section{Attention, Mindwandering, and Mood}

2013) and extend these both to duration of mindwandering episodes and to external distractions.

Although as we discuss earlier (in 4.1) all report-based measures of distraction and mindwandering require the subject's conscious awareness that they are either being distracted (e.g. by some task-irrelevant stimulus), or that their mind has wandered off, we note that providing duration estimations is also subject to a person's time perception and estimation abilities (e.g. Eagleman, 2008 for review). Importantly, none of our results rely on the absolute levels of distraction duration reported, or on the presence or duration of specific distractors. Instead our results demonstrate the relationship between distraction and mindwandering durations to each other, and to levels of happiness. We find that these relationships persist despite the variation in absolute levels of different distractions within and across individuals. The patterns in the results also hold when only shorter (up to 5 minutes) durations are reported, which suffer less from reduced ability to estimate time durations compared to longer durations. Overall, the study of frequency and duration of attention failure are complementary research strands, both of which will need to be pursued for a full understanding of the experience and consequences of different attention states. 
Attention, Mindwandering, and Mood

\section{Acknowledgements}

We thank Danielle Bagri for help with the data collection. 
Attention, Mindwandering, and Mood

Data availability statement. The data that support the findings of this study are available from the corresponding author, $\mathrm{MH}$, upon request. 
Attention, Mindwandering, and Mood

Declarations of interest: None 


\section{Attention, Mindwandering, and Mood}

\section{References}

Argyle, M., \& Crossland, J. (1987). The dimensions of positive emotions. British Journal of Social Psychology, 26(2), 127-137.

Brown, K. W., \& Ryan, R. M. (2003). The benefits of being present: mindfulness and its role in psychological well-being. Journal of personality and social psychology, 84(4), 822.

Burt, R. S. (1987). A note on strangers, friends and happiness. Social networks, 9(4), 311331.

Cohen, A. O., Breiner, K., Steinberg, L., Bonnie, R. J., Scott, E. S., Taylor-Thompson, K., ... \& Silverman, M. R. (2016). When is an adolescent an adult? Assessing cognitive control in emotional and nonemotional contexts. Psychological Science, 27(4), 549-562.

Cornblatt, B. A., Lenzenweger, M. F., \& Erlenmeyer-Kimling, L. (1989). The continuous performance test, identical pairs version: II. Contrasting attentional profiles in schizophrenic and depressed patients. Psychiatry research, 29(1), 65-85.

Csikszentmihalyi, M., \& Larson, R. (2014). Validity and reliability of the experiencesampling method. In Flow and the foundations of positive psychology (pp. 35-54). Springer, Dordrecht.

de Fockert, J. W., Rees, G., Frith, C. D., \& Lavie, N. (2001). The role of working memory in visual selective attention. Science (New York, NY), 291(March), 1803-1806. http://doi.org/10.1126/science.1056496

Deng, Y. Q., Li, S., \& Tang, Y. Y. (2014). The Relationship Between Wandering Mind, Depression and Mindfulness. Mindfulness, 5(2), 124-128. https://doi.org/10.1007/s12671-012-0157-7 


\section{Attention, Mindwandering, and Mood}

Diener, E. (2000). Subjective well-being: The science of happiness and a proposal for a national index. American psychologist, 55(1), 34.

Diener, E., Sandvik, E., Seidlitz, L., \& Diener, M. (1993). The relationship between income and subjective well-being: Relative or absolute?. Social indicators research, 28(3), 195223.

Eagleman, D. M. (2008). Human time perception and its illusions. Current opinion in neurobiology, 18(2), 131-136.

Faul, F., Erdfelder, E., Buchner, A., \& Lang, A.-G. (2009). Statistical power analyses using $\mathrm{G}^{*}$ Power 3.1: Tests for correlation and regression analyses. Behavior Research Methods, 41, 1149-1160.

Forster, S., \& Lavie, N. (2007). High Perceptual Load Makes Everybody Equal. Psychological Science, 18(5), 377-381. https://doi.org/ISSN: 0956-7976 ; E-ISSN: $1467-9280$

Forster, S., \& Lavie, N. (2008). Attentional capture by entirely irrelevant distractors. Visual Cognition, 16(2-3), 200-214. https://doi.org/10.1080/13506280701465049

Forster, S., \& Lavie, N. (2008). Failures to ignore entirely irrelevant distractors: the role of load. Journal of Experimental Psychology. Applied, 14(1), 73-83. https://doi.org/10.1037/1076-898X.14.1.73

Forster, S., \& Lavie, N. (2009). Harnessing the wandering mind: The role of perceptual load. Cognition, 111(3), 345-355. https://doi.org/10.1016/j.cognition.2009.02.006

Forster, S., \& Lavie, N. (2014). Distracted by your mind? Individual differences in distractibility predict mind wandering. Journal of Experimental Psychology. Learning, Memory, and Cognition, 40(1), 251-260. https://doi.org/10.1037/a0034108 


\section{Attention, Mindwandering, and Mood}

Forster, S., \& Lavie, N. (2016). Establishing the Attention-Distractibility Trait. Psychological Science, 27(2), 203-212. http://doi.org/10.1177/0956797615617761

Frank, D. J., Nara, B., Zavagnin, M., Touron, D. R., \& Kane, M. J. (2015). Validating older adults' reports of less mind-wandering: An examination of eye movements and dispositional influences. Psychology and Aging, 30(2), 266.

Franklin, M. S., Mrazek, M. D., Anderson, C. L., Johnston, C., Smallwood, J., Kingstone, A., \& Schooler, J. W. (2014). Tracking Distraction: The Relationship Between MindWandering, Meta-Awareness, and ADHD Symptomatology. Journal of Attention Disorders, 1-12. http://doi.org/10.1177/1087054714543494

Franklin, M. S., Mrazek, M. D., Anderson, C. L., Smallwood, J., Kingstone, A., \& Schooler, J. W. (2013). The silver lining of a mind in the clouds: interesting musings are associated with positive mood while mind-wandering. Frontiers in Psychology, 4(August), 1-5. http://doi.org/10.3389/fpsyg.2013.00583

Glass, A. L., \& Kang, M. (2018). Dividing attention in the classroom reduces exam performance. Educational Psychology, O(0), 14. http://doi.org/10.1080/01443410.2018.1489046

Gohier, B., Ferracci, L., Surguladze, S. A., Lawrence, E., El Hage, W., Kefi, M. Z., ... \& Le Gall, D. (2009). Cognitive inhibition and working memory in unipolar depression. Journal of affective disorders, 116(1-2), 100-105.

Gotlib, I. H., \& McCann, C. D. (1984). Construct accessibility and depression: An examination of cognitive and affective factors. Journal of Personality and Social Psychology, 47(2), 427. 


\section{Attention, Mindwandering, and Mood}

Harris, R. J. (2001). A primer of multivariate statistics. Psychology Press.

Helliwell, J., Layard, R., \& Sachs, J. (2017). World Happiness Report 2017, New York: Sustainable Development Solutions Network.

Jackson, J. D., \& Balota, D. A. (2012). Mind-wandering in younger and older adults: Converging evidence from the sustained attention to response task and reading for comprehension. Psychology and Aging, 27(1), 106.

Kane, M. J., Brown, L. H., McVay, J. C., Silvia, P. J., Myin-Germeys, I., \& Kwapil, T. R. (2007). For whom the mind wanders, and when: An experience-sampling study of working memory and executive control in daily life. Psychological science, 18(7), 614621.

Kane, M. J., Gross, G. M., Chun, C. A., Smeekens, B. A., Meier, M. E., Silvia, P. J., \& Kwapil, T. R. (2017). For whom the mind wanders, and when, varies across laboratory and daily-life settings. Psychological science, 28(9), 1271-1289.

Kane, M. J., Meier, M. E., Smeekens, B. A., Gross, G. M., Chun, C. A., Silvia, P. J., \& Kwapil, T. R. (2016). Individual differences in the executive control of attention, memory, and thought, and their associations with schizotypy. Journal of Experimental Psychology: General, 145(8), 1017.

Killingsworth, M. A., \& Gilbert, D. T. (2010). A wandering mind is an unhappy mind. Science (New York, N.Y.), 330, 932.

Kline, R. B. (2015). Principles and practice of structural equation modeling. Guilford publications.

Klinger, E., Gregoire, K. C., \& Barta, S. G. (1973). Physiological correlates of mental activity: Eye movements, alpha, and heart rate during imagining, suppression, concentration, search, and choice. Psychophysiology, 10(5), 471-477. 


\section{Attention, Mindwandering, and Mood}

Krawietz, S. A., Tamplin, A. K., \& Radvansky, G. A. (2012). Aging and mind wandering during text comprehension. Psychology and aging, 27(4), 951.

Kuznekoff, J. H., \& Titsworth, S. (2013). The Impact of Mobile Phone Usage on Student Learning. Communication Education, 62(3), 233-252. http://doi.org/10.1080/03634523.2013.767917

Lavie, N. (1995). Perceptual load as a necessary condition for selective attention. Journal of Experimental Psychology. Human Perception and Performance, 21(3), 451-68.

Lavie, N. (2000). Selective attention and cognitive control: Dissociating attentional functions through different types of load. Attention and performance XVIII, 175-194.

Lavie, N. (2005). Distracted and confused?: Selective attention under load. Trends in Cognitive Sciences, 9(2), 75-82. https://doi.org/10.1016/j.tics.2004.12.004

Lavie, N. (2010). Attention, Distraction, and Cognitive Control Under Load. Current Directions in Psychological Science, 19(3), 143-148.

Lavie, N., \& Cox, S. (1997). On the Efficiency of Visual Selective Attention: Efficient Visual Search Leads to Inefficient Distractor Rejection. Psychological Science, 8(5), 395-396. https://doi.org/10.1111/j.1467-9280.1997.tb00432.x

Lavie, N., Hirst, A., de Fockert, J. W., \& Viding, E. (2004). Load theory of selective attention and cognitive control. Journal of Experimental Psychology: General, 133(3), 339-354. https://doi.org/10.1037/0096-3445.133.3.339

Levinson, D. B., Smallwood, J., \& Davidson, R. J. (2012). The persistence of thought: evidence for a role of working memory in the maintenance of task-unrelated thinking. Psychological science, 23(4), 375-380. 


\section{Attention, Mindwandering, and Mood}

Lu, L. (1999). Personal or environmental causes of happiness: A longitudinal analysis. The Journal of Social Psychology, 139(1), 79-90.

Maillet, D., Beaty, R. E., Jordano, M. L., Touron, D. R., Adnan, A., Silvia, P. J., ... \& Kane, M. J. (2018). Age-related differences in mind-wandering in daily life. Psychology and aging, 33(4), 643.

Mason, M. F., Norton, M. I., Van Horn, J. D., Wegner, D. M., Grafton, S. T., \& Macrae, C. N. (2007). Wandering minds: the default network and stimulus-independent thought. Science, 315(5810), 393-395.

McVay, J. C., \& Kane, M. J. (2009). Conducting the Train of Thought: Working Memory Capacity, Goal Neglect, and Mind Wandering in an Executive-Control Task. Journal of Experimental Psychology: Learning, Memory, and Cognition, 35(1), 196-204. https://doi.org/10.1037/a0014104.Conducting

McVay, J. C., \& Kane, M. J. (2010). Does Mind Wandering Reflect Executive Function or Executive Failure? Comment on and Smallwood and Schooler (2006) Watkins (2008). Psychological Bulletin, 136(2), 188-207. https://doi.org/10.1037/a0018298.Does

McVay, J. C., Kane, M. J., \& Kwapil, T. R. (2009). Tracking the train of thought from the laboratory into everyday life: An experience-sampling study of mind wandering across controlled and ecological contexts. Psychonomic Bulletin \& Review, 16(5), 857-63. http://doi.org/10.3758/PBR.16.5.857

McVay, J. C., Meier, M. E., Touron, D. R., \& Kane, M. J. (2013). Aging ebbs the flow of thought: Adult age differences in mind wandering, executive control, and selfevaluation. Acta psychologica, 142(1), 136-147.

Mialet, J., Pope, H. G., \& Yurgelun-Todd, D. (1996). Impaired attention in depressive states: a non-specific deficit? Psychological Medicine, 26, 1009-1020. 


\section{Attention, Mindwandering, and Mood}

Mrazek, M. D., Phillips, D. T., Franklin, M. S., Broadway, J. M., \& Schooler, J. W. (2013). Young and restless: validation of the Mind-Wandering Questionnaire (mindwanderingQ) reveals disruptive impact of mind-wandering for youth. Frontiers in Psychology, 4(August), 1-7. https://doi.org/10.3389/fpsyg.2013.00560

Nguyen, Q. C., Li, D., Meng, H. W., Kath, S., Nsoesie, E., Li, F., \& Wen, M. (2016). Building a national neighborhood dataset from geotagged Twitter data for indicators of happiness, diet, and physical activity. JMIR public health and surveillance, 2(2).

Office for National Statistics. (2015) Annual Survey of Hours and Earnings (ASHE) average annual earnings for 2015 .

Office for National Statistics. (2017) Population Estimates for UK, England and Wales, Scotland and Northern Ireland, Mid-2016.

Olesen, P. J., Macoveanu, J., Tegnér, J., \& Klingberg, T. (2006). Brain activity related to working memory and distraction in children and adults. Cerebral cortex, 17(5), 1047 1054.

Ottaviani, C., \& Couyoumdjian, A. (2013). Pros and cons of a wandering mind: A prospective study. Frontiers in Psychology, 4(AUG), 1-9. http://doi.org/10.3389/fpsyg.2013.00524

Oulasvirta, A., Rattenbury, T., Ma, L., \& Raita, E. (2012). Habits make smartphone use more pervasive. Personal and Ubiquitous Computing, 16(1), 105-114.

Pacheco-Unguetti, A. P., \& Parmentier, F. B. (2014). Sadness increases distraction by auditory deviant stimuli. Emotion, 14(1), 203.

Poerio, G. L., Totterdell, P., \& Miles, E. (2013). Mind-wandering and negative mood: Does one thing really lead to another?. Consciousness and cognition, 22(4), 1412-1421. 


\section{Attention, Mindwandering, and Mood}

Rees, G., Frith, C. D., \& Lavie, N. (1997). Modulating irrelevant motion perception by varying attentional load in an unrelated task. Science (New York, N.Y.), 278(5343), 1616-1619. http://doi.org/10.1126/science.278.5343.1616

Robison, M. K., \& Unsworth, N. (2015). Working Memory Capacity Offers Resistance to Mind-Wandering and External Distraction in a Context-Specific Manner. Applied Cognitive Psychology, 690(July), 680-690.

Roye, A., Jacobsen, T., \& Schröger, E. (2007). Personal significance is encoded automatically by the human brain: an event-related potential study with ringtones. European Journal of Neuroscience, 26(3), 784-790.

Røysamb, E., Tambs, K., Reichborn-Kjennerud, T., Neale, M. C., \& Harris, J. R. (2003). Happiness and health: environmental and genetic contributions to the relationship between subjective well-being, perceived health, and somatic illness. Journal of personality and social psychology, 85(6), 1136.

Ruby, F. J. M., Smallwood, J., Engen, H. G., \& Singer, T. (2013). How Self-Generated Thought Shapes Mood: The Relation between Mind-Wandering and Mood Depends on the Socio-Temporal Content of Thoughts. PLoS ONE, 8(10), e77554. https://doi.org/10.1371/journal.pone.0077554

Seli, P., Carriere, J. S. A., \& Smilek, D. (2014). Not all mind wandering is created equal: dissociating deliberate from spontaneous mind wandering. Psychological Research, 79(5), 750-758. https://doi.org/10.1007/s00426-014-0617-x

Seli, P., Risko, E. F., \& Smilek, D. (2016). On the Necessity of Distinguishing Between Unintentional and Intentional Mind Wandering. Psychological Science. https://doi.org/10.1177/0956797616634068 


\section{Attention, Mindwandering, and Mood}

Singer, J. L., \& Antrobus, J. S. (1970). Imaginal processes inventory. ETS m 1977.

Smallwood, J. (2013). Searching for the Elements of Thought: Reply to Franklin, Mrazek, Broadway, and Schooler (2013). Psychological Bulletin, 139(3), 542-547. http://doi.org/10.1037/a0031019

Smallwood, J., Davies, J. B., Heim, D., Finnigan, F., Sudberry, M., O'Connor, R., \& Obonsawin, M. (2004). Subjective experience and the attentional lapse: Task engagement and disengagement during sustained attention. Consciousness and cognition, 13(4), 657-690.

Smallwood, J., McSpadden, M., \& Schooler, J. W. (2008). When attention matters: The curious incident of the wandering mind. Memory \& Cognition, 36(6), 1144-1150. https://doi.org/10.3758/MC.36.6.1144

Smallwood, J., O'Connor, R. C., Sudbery, M. V., \& Obonsawin, M. (2007). Mind-wandering and dysphoria. Cognition and Emotion, 21(4), 816-842.

Smallwood, J., \& O'Connor, R. C. (2011). Imprisoned by the past: unhappy moods lead to a retrospective bias to mind wandering. Cognition \& emotion, 25(8), 1481-1490.

Smallwood, J., \& Schooler, J. W. (2006). The restless mind. Psychological Bulletin, 132(6), 946-958. https://doi.org/10.1037/0033-2909.132.6.946

Smallwood, J., \& Schooler, J. W. (2015). The Science of Mind Wandering: Empirically Navigating the Stream of Consciousness. Annual Review of Psychology, 66(1), 487-518. http://doi.org/10.1146/annurev-psych-010814-015331

Song, X., \& Wang, X. (2012). Mind Wandering in Chinese Daily Lives - An Experience Sampling Study. PLoS ONE, 7(9), e44423. http://doi.org/10.1371/journal.pone.0044423 


\section{Attention, Mindwandering, and Mood}

Souter, M. A., \& Miller, M. D. (2007). Do animal-assisted activities effectively treat depression? A meta-analysis. Anthrozoös, 20(2), 167-180.

Stawarczyk, D., \& D’Argembeau, A. (2016). Conjoint influence of mind-wandering and sleepiness on task performance. Journal of Experimental Psychology: Human Perception and Performance, 42(10), 1587-1600. https://doi.org/10.1037/xhp0000254

Stawarczyk, D., Majerus, S., \& D'Argembeau, A. (2013). Concern-induced negative affect is associated with the occurrence and content of mind-wandering. Consciousness and Cognition, 22(2), 442-448. https://doi.org/10.1016/j.concog.2013.01.012

Stawarczyk, D., Majerus, S., Catale, C., \& D’Argembeau, A. (2014). Relationships between mind-wandering and attentional control abilities in young adults and adolescents. Acta Psychologica, 148, 25-36. https://doi.org/10.1016/j.actpsy.2014.01.007

Stawarczyk, D., Majerus, S., Maj, M., Van der Linden, M., \& D’Argembeau, A. (2011). Mind-wandering: Phenomenology and function as assessed with a novel experience sampling method. Acta Psychologica, 136(3), 370-381. https://doi.org/10.1016/j.actpsy.2011.01.002

Stawarczyk, D., Majerus, S., Maquet, P., \& D'Argembeau, A. (2011). Neural correlates of ongoing conscious experience: both task-unrelatedness and stimulus-independence are related to default network activity. PloS one, 6(2), e16997

Stawarczyk, D., Majerus, S., Van der Linden, M., \& D'Argembeau, A. (2012). Using the daydreaming frequency scale to investigate the relationships between mind-wandering, psychological well-being, and present-moment awareness. Frontiers in psychology, 3, 363.

Stevens, J. P. (2012). Exploratory and confirmatory factor analysis. In Applied multivariate statistics for the social sciences (pp. 337-406). Routledge. 


\section{Attention, Mindwandering, and Mood}

Szpunar, K. K., Khan, N. Y., \& Schacter, D. L. (2013). Interpolated memory tests reduce mind wandering and improve learning of online lectures. Proceedings of the National Academy of Sciences, 110(16), 6313-6317. https://doi.org/10.1073/pnas.1221764110

Unsworth, N., \& McMillan, B. D. (2014). Similarities and differences between mindwandering and external distraction: A latent variable analysis of lapses of attention and their relation to cognitive abilities. Acta Psychologica, 150, 14-25. https://doi.org/10.1016/j.actpsy.2014.04.001

Unsworth, N., \& McMillan, B. D. (2017). Attentional disengagements in educational contexts: a diary investigation of everyday mind-wandering and distraction. Cognitive Research: Principles and Implications, 2(1), 32. http://doi.org/10.1186/s41235-0170070-7

Unsworth, N., Brewer, G. A., \& Spillers, G. J. (2012). Variation in cognitive failures: An individual differences investigation of everyday attention and memory failures. Journal of Memory and Language, 67(1), 1-16. http://doi.org/10.1016/j.jml.2011.12.005

Unsworth, N., McMillan, B. D., Brewer, G. A., \& Spillers, G. J. (2012). Everyday Attention Failures: An Individual Differences Investigation. Journal of Experimental Psychology: Learning, Memory, and Cognition, 38(6), 1765-1772. https://doi.org/10.1037/a0028075

Unsworth, N., \& Robison, M. K. (2016). Pupillary correlates of fluctuations in sustained attention. Cognitive, Affective and Behavioral Neuroscience, 16(4), 601-615. http://doi.org/10.1162/jocn_a 01251

Van Calster, L., D'Argembeau, A., \& Majerus, S. (2018). Measuring individual differences in internal versus external attention: The attentional style questionnaire. Personality and Individual Differences, 128, 25-32. 
Attention, Mindwandering, and Mood

Weinstein, Y. (2017). Mind-wandering, how do I measure thee with probes? Let me count the ways. Behavior research methods, 1-20. 